\title{
Análisis multiescala de indicadores arqueológicos de Tlajinga, Teotihuacan (México). Desde la percepción remota a la microscopía
}

\author{
Jorge Blancas, Luis Barba, David Carballo, Elizabeth Solleiro Rebolledo, Sergey Sedov, Jaime Díaz
}

\section{RESUMEN}

\section{Jorge Blancas}

jorgeblancas@unam.mx

Posgrado en Ciencias de la Tierra, UNAM, Laboratorio de Prospección Arqueológica, 04510 Coyoacán, CDMX, México.

\section{Jorge Blancas}

Luis Barba

Laboratorio de Prospección Arqueológica,

UNAM, 04510 Coyoacán, CDMX, México.

\section{David Carballo}

Department of Anthropology and Archaeology Program, Boston University, 02215, United States of America.

\section{Elizabeth Solleiro Rebolledo} Sergey Sedov Jaime Díaz

Departamento de Ciencias Ambientales y del Suelo, Instituto de Geología, UNAM, 06400, CDMX, México.
BOL. SOC. GEOL. MEX. 2019

VOL. 71 NO. 2

P. $457-479$

http://dx.doi.org/10.18268/BSGM2019v7 ln2al4

Manuscrito recibido: Diciembre 29, 2017. Manuscrito corregido: Junio 14, 2018. Manuscrito aceptado: Agosto 3, 2018.
El barrio de Tlajinga es un área ubicada al sur de la ciudad de Teotihuacán, Estado de México, que preserva materiales prehispánicos diseminados en distintas zonas del terreno, así como estructuras arqueológicas enterradas. Las partículas del suelo, al mezclarse con materiales arqueológicos tales como piedra, estuco, cerámica y fragmentos de murales, enriquecen el suelo principalmente con carbonato de calcio, lo que contribuye al aumento de la reflectancia en distintas zonas del terreno, principalmente en zonas donde había estructuras arqueológicas. Este fenómeno es registrado desde un nivel sinóptico por los sensores remotos actuales, con mayor resolución espectral, espacial y radiométrica, correlacionándose a una menor escala con la espectrorradiometría y la micromorfología de los suelos. De esta forma se identificaron algunos minerales presentes en los pisos y muros, principalmente el estuco arqueológico, ahora transformado en pequeñas partículas de carbonato de calcio. La fluorescencia (FRX) y difracción de rayos $\mathrm{X}$ (DRX) complementaron los resultados de la percepcción remota, la espectrorradiometría y la micromorfología, identificando la composición elemental de las partículas del suelo y los minerales asociados, de la que sobresale el carbonato de calcio, un compuesto muy importante utilizado para el recubrimiento de pisos y edificios durante la época teotihuacana.

Palabras clave: Percepción remota, micromorfología, espectrorradiometría, fluorescencia de rayos $x$, difracción de rayos $x$.

\section{ABSTRACT}

The Tlaïnga Barrio is a domestic area situated in the south of Teotihuacan, Estado de México, where preserves original surface materials as well as buried archaeological structures are preserved. Original soil particles mixed with archaeological materials such as stone, stucco, ceramics, and mural fragments enrich the soil mainly with calcium carbonate, contributing to the increase in reflectance in different areas of the terrain, mainly in nearby areas where there were archaeological structures. This is recorded from a synoptic level by the modern remote sensors, with higher spectral, spatial, and radiometric resolution, correlating it to a smaller scale with soil micromorphology analysis. In this way, some minerals present in the floors and walls were identified, mainly the archaeological stucco now transformed into small particles of calcium carbonate. $X$-ray fluorescence (XFRF) and X-ray diffraction (XRD) complemented the results of remote sensing, spectrometry and micromorphology, identifying the elemental composition of soil particles and associated minerals, mainly calcium carbonate, that were used live in coatings on floors and buildings during the Teoti huacan era.

Key words: Remote sensing, micromorphology, spectroradiometry, $x$-ray fluorescence, $x$-ray diffraction. 


\section{Introducción}

Este trabajo incluye estudios arqueológicos, técnicas de percepción remota, composición química y mineralógica del suelo y prospección geofísica. Una parte de los estudios se enfocaron en establecer el grado de similitud entre los materiales arqueológicos diseminados en distintas zonas del terreno que ocupa actualmente el barrio de Tlajinga, con las anomalías espectrales en las imágenes satelitales, y con el contenido químico y mineralógico de las partículas del suelo derivadas de actividades humanas, principalmente de la época Teotihuacana. Fue importante llevar a cabo la investigación de manera inmediata, debido a la inminente urbanización de la zona de estudio.

Se pretende ampliar el conocimiento de una parte pequeña de la franja sureña de la gran metrópoli Teotihuacana, conocida como el Barrio de Tlajinga, con el propósito de identificar con mayor detalle los cambios que un asentamiento humano produce en la superficie y en el subsuelo que ocupa.

La investigación está planteada para verificar la correspondencia entre el contenido químico y mineralógico del suelo, derivado de actividades humanas en el pasado, con las anomalías en la superficie del suelo, extraídas a partir del tratamiento de imágenes satelitales obtenidas con sensores remotos de alta resolución. Para tales objetivos se utilizaron como elementos principales: imágenes satelitales de alta resolución, espectrorradiometría, micromorfología por láminas delgadas, la fluorescencia y difracción de rayos $\mathrm{X}$, y se estableció una metodología para el estudio de sitios arqueológicos en el altiplano central de México desde una escala sinóptica hasta una microscópica.

\subsection{ANTEGEDENTES ARQUEOLÓGICOS}

Uno de los grandes trabajos interdisciplinarios en el Valle de Teotihuacan fue dirigido por Manuel Gamio a principios del siglo XX; en él se involucraron geólogos, antropólogos, arquitectos, ingenieros e indigenistas (Gamio, 1979).
La presencia de barrios en la antigua ciudad fue planteada por numerosos autores, pero fue el Proyecto de Mapeo de Teotihuacan, Teotihuacan Mapping Project (TMP), el que empezó a clasificar de manera sistemática los diversos conjuntos departamentales (Millon, 1973; 1976; 1981).

Hasta el momento, los dos barrios más estudiados en Teotihuacan son La Ventilla, por las investigaciones de Cabrera (1996; 1998; Cabrera et al., 2008) y Teopancazco, por las investigaciones de Manzanilla (2006; 2007; 2009; 2011).

El Barrio de Tlajinga ofrece altas posibilidades de contribuir a resolver debates importantes acerca de la relación entre unidades domésticas y la especialización tecnológica de la obsidiana (Carballo, 2013). Las extensas excavaciones que se realizaron en Tlajinga, en el sector 33: S3W1 o "Tlajinga 33" en 1980 con un proyecto de la Pennsylvania State University, dirigido por William Sanders, proporcionaron una perspectiva detallada de un conjunto departamental, tanto en su organización social y espacial (Widmer, 1987; 1993) como en las especializaciones artesanales, particularmente con respecto a la lapidaria (Widmer, 1991) y la cerámica (Sullivan, 2006).

\subsection{INVESTIGAGIONES GON LA PERGEPGIÓN REMOTA EN EL VALLE DE TEOTIHUACAN}

La percepción remota es una herramienta valiosa para la investigación arqueológica; actualmente existe mayor disponibilidad de imágenes y los sensores de alta resolución ofrecen una primera aproximación al estudio de un sitio arqueológico sobre la superficie del suelo. La información multiespectral con alta resolución espacial permite detectar estructuras constructivas, sobre e indirectamente bajo la superficie del suelo, asociadas con modificaciones al paisaje antiguo. Esta información está ligada principalmente a la composición química y mineralógica del suelo.

Un estudio pionero en México se realizó en Oztoyahualco, al noroeste de Teotihuacan. En este sitio se utilizó la percepción remota para adquirir imágenes aéreas con un globo cautivo tipo zeppelin 


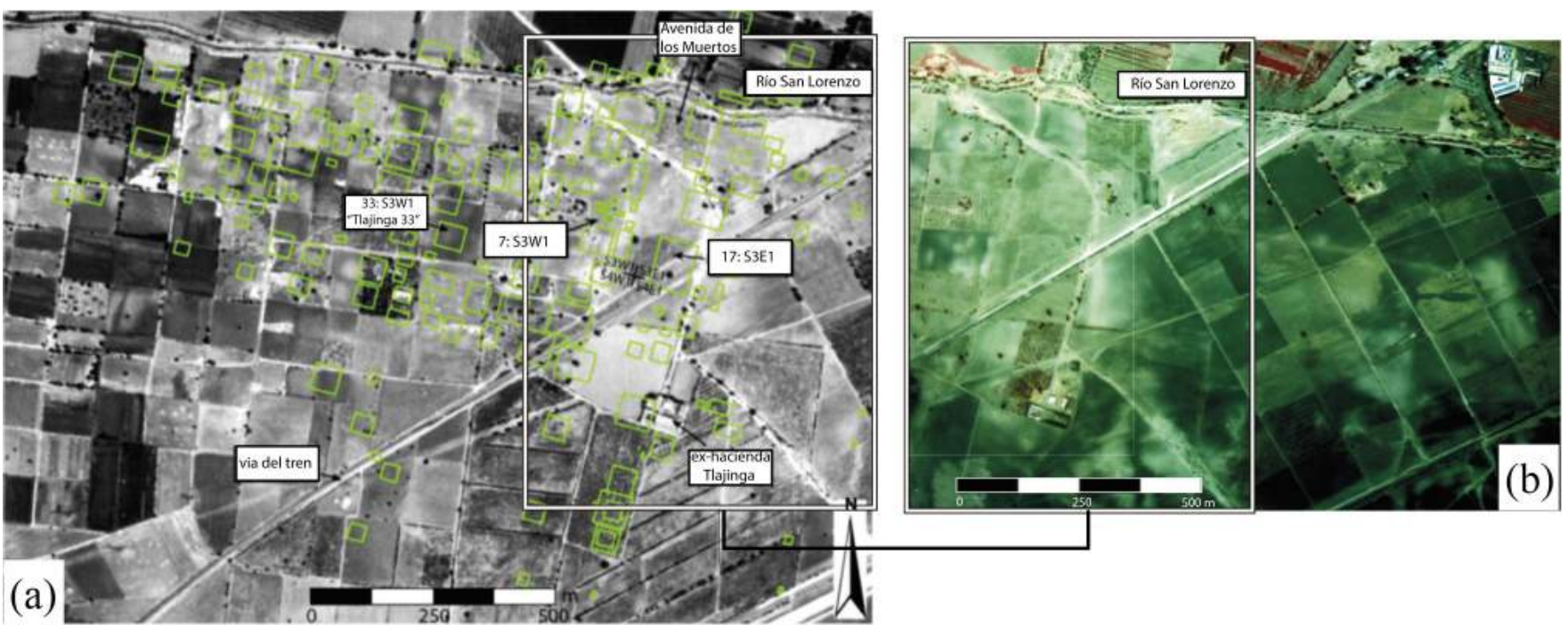

Figura 1 (a) Mapa del Barrio de Tlajinga con distintos sectores y las estructuras cuadriculares según Millon (1973), cortesía proyecto PATT. (b) Imagen infrarroja de la parte este de Tlajinga donde se detectan trayectorias de canales agrícolas prehispánico (Nichols, 1988).

en las bandas visible e infrarrojo, y fue la primera vez que se estableció la relación entre las manchas blancas en la superficie de suelo y la concentración de carbonatos de calcio provenientes de la cal prehispánica (Ortiz y Barba 1993).

En Tlajinga, las investigaciones fuera del sector 33: S3W1 combinaron el análisis de fotografías aéreas y las excavaciones, las cuales aportaron datos importantes sobre la trayectoria de los canales arqueológicos agrícolas al norte y al este del barrio, entre el Río San Lorenzo y la Barranca San Mateo (Nichols, 1988).

Este fue el antecedente más directo de la aplicación de la percepción remota en la búsqueda de canales, especialmente con imágenes infrarrojas aéreas, ligadas a una aplicación arqueológica en la zona (Figura 1).

Estudios más recientes combinaron imágenes multiespectrales de distintos satélites - Landsat ETM+, Spot 5 y QuickBird - para un sitio del Formativo ubicado en el estado de Tlaxcala, llamado La Laguna (Blancas, 2012), en donde se identificaron, a través del tratamiento de las imágenes, zonas con reflectancias particulares, de tal forma que ello permitió clasificar el área que no tiene el suelo original, mostrando las zonas culturalmente alteradas, principalmente de la ocupación del periodo Formativo.

\section{2. Área de estudio}

El Barrio de Tlajinga se ubica en la parte sur del Valle de Teotihuacan, al sur de la zona monumental, siguiendo el trazo de la Calzada de los Muertos y a $1.5 \mathrm{~km}$ de distancia de la Ciudadela, las coordenadas aproximadas del centro del sitio son: 515477 m E, 2174891 m N (9851'8.49'O, $19^{\circ} 40^{\prime} 9.37$ "N).La imagen de la (Figura 2) fue elaborada con la composición de la imagen pancromática del sensor de QuickBird, y en amarillo el trazo de la Ciudad dividida en cuadrantes según el mapa elaborado por Millon (1973).

\subsection{ENTORNO GEOLÓGICO Y GEOMORFOPEDOLÓGICO DEL VALLE DE TEOTIHUAGAN}

La geología, la geomorfología y los suelos del Valle de Teotihuacan nos indican el origen de los materiales arqueológicos y la disponibilidad de la 
materia prima para la construcción de la ciudad y sus barrios como el de Tlajinga. Asimismo, la extracción de tezontle de las canteras cercanas, la utilización de grandes volúmenes de suelo y la de madera para la construcción y el combustible para la quema de la cal proveniente de las rocas calizas para cubrir los edificios, tuvieron un impacto significativo en el paisaje circundante (Barba, 1995). La geología de la zona consta principalmente de rocas andesítico-basálticas localizadas hacia el norte (Gerro Gordo), flujos de lava basálticos en la parte sureste, rocas dacíticas en el sur (Sierra de Patlachique) y una planicie de origen fluvial-lacustre formada por material clástico no consolidado (Vázquez y Jaimes, 1989).

El análisis geomorfológico del Valle de Teotihuacan sugiere un paisaje modificado por la actividad humana a lo largo del tiempo, creando vías de comunicación y asentamientos humanos de distintos tamaños, parcelas agrícolas y canales. A través del estudio del paisaje, las unidades geomorfológicas, basadas en su forma, pendiente, procesos de denudación y sedimentación, material original y vegetación y uso actual son: planicies y terrazas aluviales, piedemonte coluvial y piedemonte aluvial (Hernández, 2007).

En las partes altas de las montañas al sur de Tlajinja (Sierra Patlachique) y hacia el norte (Cerro Gordo), los suelos corresponden con Leptosoles. En las zonas medias y bajas del área de estudio, dominan los Phaeozems y Cambisoles, mientras que en las partes más bajas de valle, los Vertisoles son los suelos predominantes (Gama-Castro et al., 2005).

\section{Materiales y métodos}

\subsection{PERGEPGIÓN REMOTA}

Para este estudio se utilizaron las imágenes del sensor GeoEye-1, con la banda pancromática de $450-800 \mathrm{~nm}$ y resolución espacial de $41 \mathrm{~cm}$. La resolución radiométrica o el número de niveles digitales de los pixeles en las imágenes fue de 11 bits. Las bandas multiespectrales con resolución espacial del $1.65 \mathrm{~m}$ correspondieron con el azul de: $450-510 \mathrm{~nm}$, verde de: $510-580 \mathrm{~nm}$, rojo de: 655 - $690 \mathrm{~nm}$ e infrarrojo cercano de: 780 $-920 \mathrm{~nm}$.

El procesamiento de las imágenes consistió en la corrección atmosférica con el método propuesto por Chavez (1996) y posteriormente se realizó la fusión de las imágenes multiespectrales con la imagen pancromática. Con esto se obtuvo la resolución espacial de la pancromática $(41 \mathrm{~cm})$, pero con el contraste cromático de las multiespectrales. Posteriormente, se hizo el análisis de componentes principales para reducir la dimensionalidad de los datos, concentrando la información no redundante de cuatro bandas $(90 \%)$ en sólo tres bandas con un menor porcentaje de correlación entre ellas (CP1, CP2, CP3).

\subsection{TRABAJO DE GAMPO}

La primera fase del trabajo de campo consistió en recolectar un total de 46 muestras de suelo en distintas zonas del terreno a partir del análisis de patrones anómalos en la imagen de componentes principales. Las muestras provienen de la parte central del sitio de Tlajinga y donde Millon interpretó un conjunto de estructuras arqueológicas a partir del levantamiento topográfico de Teotihuacan (Millon, 1973).

Además de las muestras de suelo, se tomaron materiales que se consideraron de referencia para comparar los resultados, como estucos procedentes de estructuras teotihuacanas, caliches (carbonato natural presente en los suelos) y suelos, como el Paleosuelo Negro San Pablo (PNSP), o Capa IV, el cual ha sido identificado y estudiado con detalle, ya que en él se asentó la cultura teotihuacana. Este suelo está caracterizado por ser de color negro con propiedades vérticas, el cual se localiza, principalmente en la planicie aluvial y tiene una edad

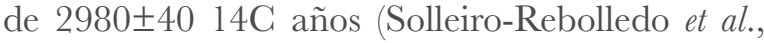
2011; Sánchez-Pérez et al., 2013). 


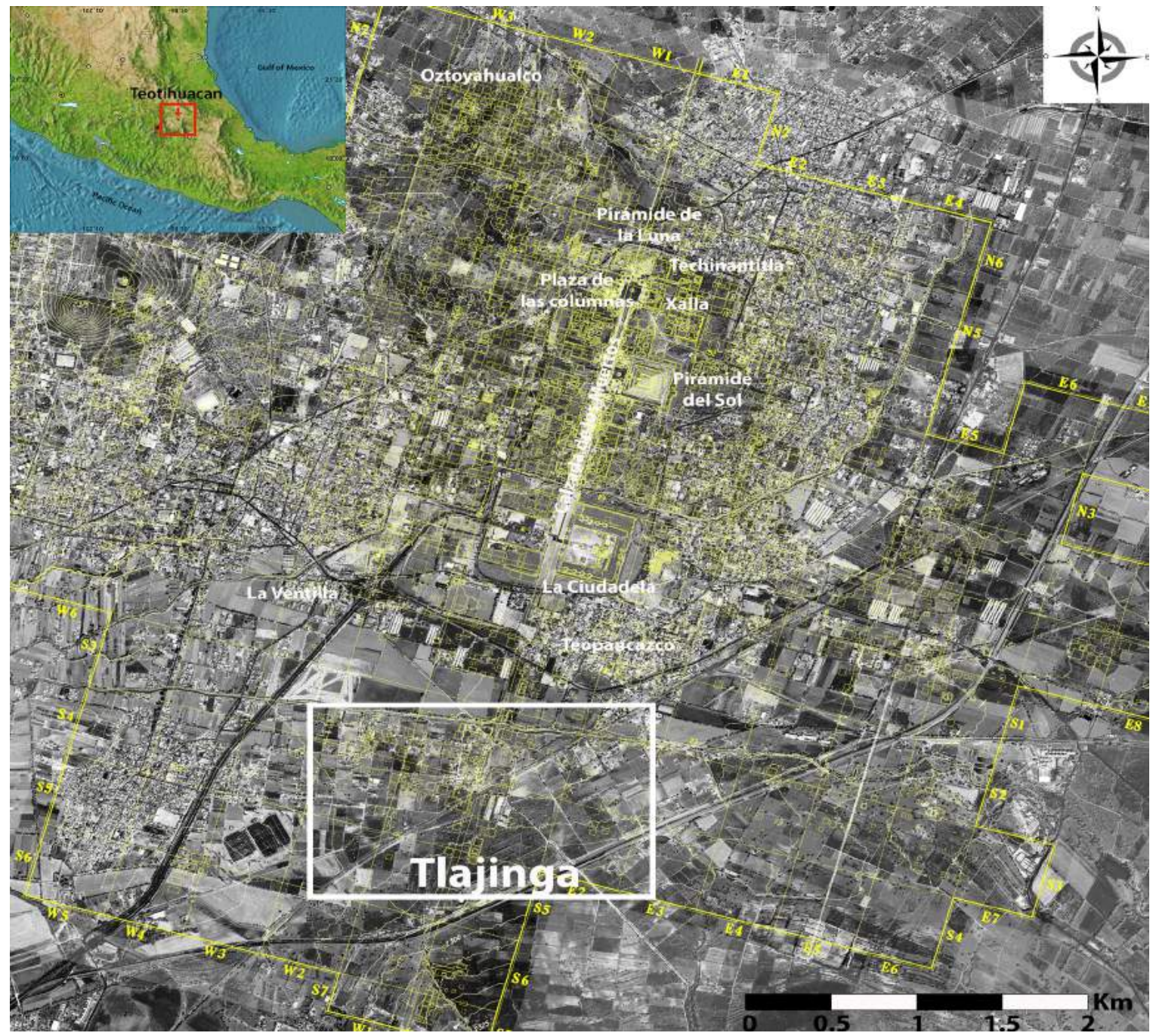

Figura 2 Imagen pancromática de Teotihuacan con la superposición del Mapa de Millon y el barrio de Tlajinga ubicado al sur de la ciudad.

\subsection{ANÁLISIS DE LABORATORIO}

La selección de muestras para su análisis y comparación con técnicas microscópicas fueron en zonas con alta y baja reflectancia, que tienen relación estrecha con las componentes CP1 y CP3, con el brillo, el contraste cromático y con la forma de las anomalías; además de su correspondencia con la topografía del terreno y las estructuras reportadas en el Mapa de Millon (1973).

Espectrorradiometría. De las 46 muestras de suelo recolectadas, se seleccionaron 19 (T1 a T19) para la medición de la reflectancia. Además, también se consideró la muestra del PNSP para obtener la respuesta espectral del suelo original, con poca o nula influencia cultural de la época teotihuacana. La reflectancia se determinó en diferentes longitudes de onda, comparando la energía reflejada con la energía incidente, utilizando un espectrorradiómetro Lab Spec Pro de la marca ASD, con un rango de medición de 350 a $2500 \mathrm{~nm}$. Para evitar la dispersión de la energía al hacer las mediciones en el laboratorio, las muestras de suelo se limpiaron y secaron por cinco días, posteriormente se molieron y homogeneizaron con un mortero de ágata. Antes de cada medición, se realizaron lecturas con 
un blanco de barita para calibrar correctamente el sensor. Además, las muestras se compactaron ligeramente para tener una superficie uniforme y así minimizar la dispersión de la energía. Se estudiaron con esta técnica veinte muestras de suelo de Tlajinga.

A partir de los resultados y de su distribución espacial con relación a las estructuras arqueológicas, establecidas en el mapa de Millon (1973), se seleccionaron 5 (T4, T5, T8, T14, T15) y un estuco de Tlajinga para los análisis químicos y mineralógicos.

Micromorfología. Las muestras de suelo y las de referencia (estuco, PNSP y caliche) se impregnaron con resina poliéster, se metieron al vacío durante cinco minutos y se dejaron reposar por dos días; posteriormente se cortaron y pulieron con sierra de diamante circular y pulidora rotativa Buehler MetaServ 2000. Finalmente, se utilizó la laminadora Buehler Petrothin para fabricar las láminas delgadas con un espesor de 30 micras. Se estudia- ron un total de doce muestras de suelo (Tabla 1). Las láminas delgadas se observaron bajo el microscopio petrográfico Olympus EX51, del Instituto de Geología, agregando una gota de glicerina (con índice de refracción de 1.47) que permitió un mejor análisis y la identificación de los minerales. Para la captura delas imágenes, se utilizó el programa Image Pro Plus.

Fluorescencia de rayos X (FRX). Las muestras recolectadas se secaron y limpiaron, posteriormente se molieron y homogeneizaron mediante un mortero de ágata y se vaciaron en portamuestras especiales para analizarlas en el equipo de FRX. El equipo utilizado fue un sistema de fluorescencia de rayos X portátil "ADIS", con tubo de rayos X de Mo Oxford Modelo XTF5011A, detector de rayos X Si-PIN con amplificador y fuente de alimentación X-123Amptek, desarrollado en el Laboratorio Nacional de Ciencias para la Investigación y Conservación del Patrimonio Cultural, LANCIC, Instituto de Física, UNAM. Este

Tabla 1. Muestras analizadas por las diferentes técnicas tanto macroscópicas como microscópicas de los materiales de estudio.

\begin{tabular}{|c|c|c|}
\hline Técnica & Objetivo & Muestras analizadas \\
\hline Percepción remota & $\begin{array}{l}\text { Detectar sinópticamente zonas con y sin } \\
\text { enriquecimiento teotihuacano }\end{array}$ & $\begin{array}{c}\text { Imagen recortada de } 1 \mathrm{~km}^{2} \text { con } 46 \text { zonas potenciales } \\
\text { seleccionadas }\end{array}$ \\
\hline Espectrorradiometría & Calcular la reflectancia promedio & $\begin{array}{c}\text { T1 a T19 (dando un total de } 19 \text { muestras) y una } \\
\text { muestra del PNSP* }\end{array}$ \\
\hline Micromorfología & $\begin{array}{c}\text { Determinar microestructura interna de los } \\
\text { materiales, así como de los minerales } \\
\text { presentes }\end{array}$ & $\begin{array}{l}\text { T4, T5, T8, T14 y T15 } \\
\text { Muestras de referencia: estuco, caliche y PNSP }\end{array}$ \\
\hline $\begin{array}{l}\text { Fluorescencia de rayos } \\
\qquad \mathrm{X}(\mathrm{FRX})\end{array}$ & Determinar contenido químico elemental & $\begin{array}{l}\text { T4, T5, T8, T14 y T15 } \\
\text { Muestras de referencia: estuco, caliche y PNSP }\end{array}$ \\
\hline $\begin{array}{l}\text { Difracción de rayos } \mathrm{X} \\
\text { (DRX) }\end{array}$ & $\begin{array}{l}\text { Detectar contenido mineralógico de las } \\
\text { principales fases minerales }\end{array}$ & $\begin{array}{l}\text { T4, T5, T8, T14 y T15 } \\
\text { Muestras de referencia: estuco, caliche y PNSP }\end{array}$ \\
\hline
\end{tabular}


equipo se usó también para la determinación de las fases minerales con difracción de rayos X. Se utilizaron patrones de referencia internacionales adquiridos por el LANCIC y otros preparados por el mismo laboratorio, de obsidiana, calcita y otros materiales.

Difracción de rayos X (DRX). Para el análisis de la composición mineralógica de los suelos muestreados, se utilizó la difracción de rayos X del LANGIC, Instituto de Física UNAM, con el objetivo de identificar las principales fases minerales y su abundancia relativa en las muestras de suelo. Para el análisis, se hicieron mediciones de muestras no orientadas en un intervalo angular $2 \theta$ de $10^{\circ}$ a $110^{\circ}$. Las muestras se molieron en mortero de ágata hasta obtener un polvo, cubriendo un área de 1 a $2 \mathrm{~cm}^{2}$, y se vaciaronn después en el portamuestras del difractómetro. Se utilizó el programa Match V.3.0 para la identificación de las fases y las bases de referencia de libre acceso de cristalografía

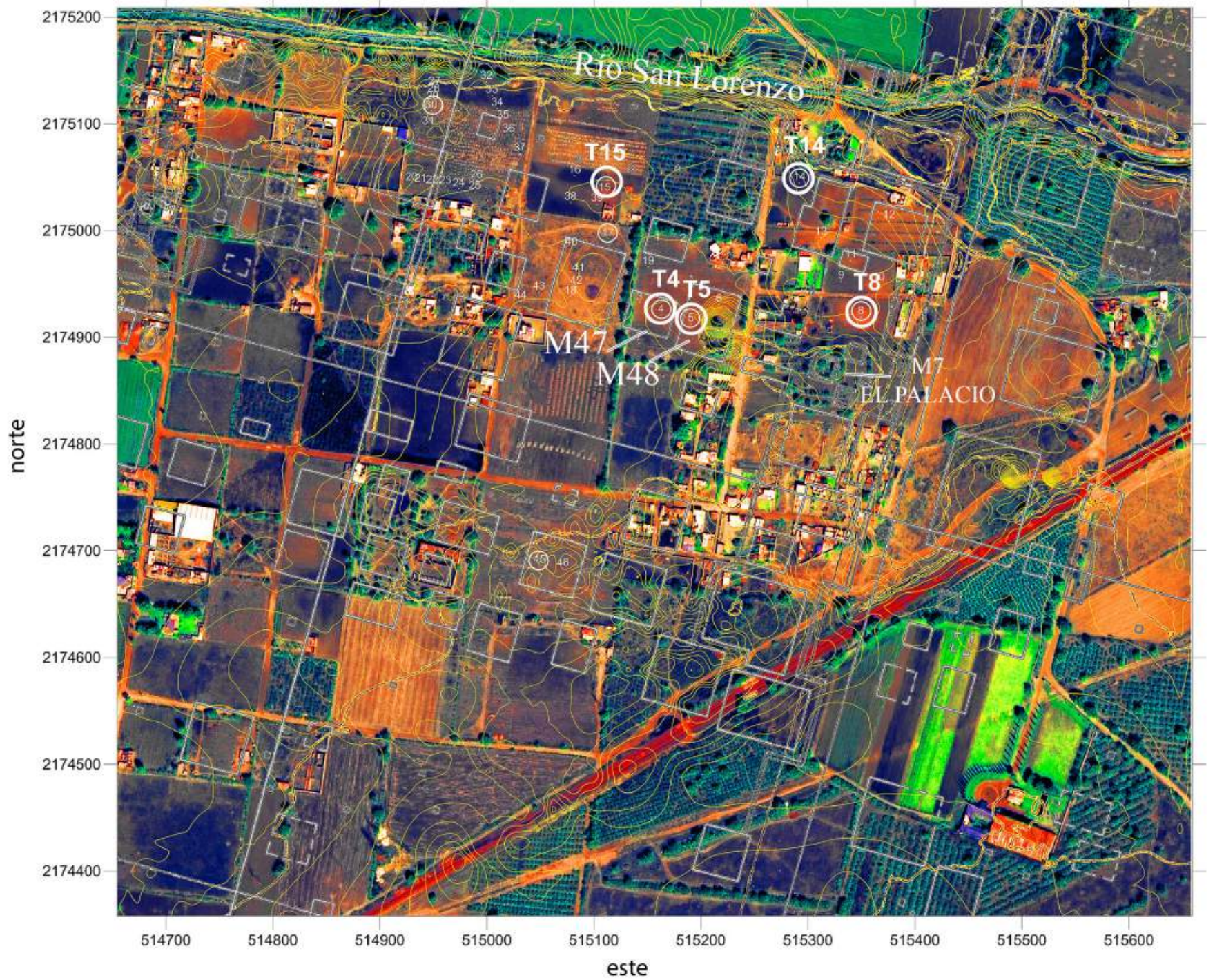

Figura 3 Imagen de componentes principales de la zona de Tlajinga con la nomenclatura (T de Tlajinga) de las muestras recolectadas para su análisis. 
(Crystallography Open Database, 2016) del International Centre for Diffraction Data (ICDD).

Tanto para el análisis de DRX como de FRX, se tomó un grupo representativo de ocho muestras de suelo; tres de ellas fueron muestras de referencia de caliche, estuco y PNSP (Tabla 1).

\section{Resultados}

\subsection{PERGEPGIÓN REMOTA}

A pesar de que en las imágenes de Tlajinga la información del pasado cultural, en forma de materiales arqueológicos dispersos, está mezclada con sedimentos y suelos actuales, fue posible extraerla a partir del tratamiento de las imágenes multiespectrales.
La composición de color mostrada está formada con las componentes principales GP1, GP2 y CP3 en los canales RGB (rojo, verde y azul), respectivamente (Figura 3). La primera aproximación al estudio se obtuvo a partir de una visión sinóptica de las anomalías observadas sobre la superficie del terreno. El grado de significación de las muestras está relacionado con las anomalías de mayor brillo y contraste cromático sobre la superficie del terreno. Numéricamente, estas zonas anómalas se relacionan directamente con las reflectancias más grandes en todas las bandas, azul (B01), verde (B02), roja (B03) e infrarroja (B04), concentrando el máximo brillo en la CP1. Por otra parte, la CP2 concentra la mayor reflectancia del suelo y la vegetación en la banda infrarroja (B04). La CP3 se relaciona directamente con las bandas verde (B02) y roja (B03). La combinación de las componentes

\section{Reflectancia promedio muestras Tlajinga}

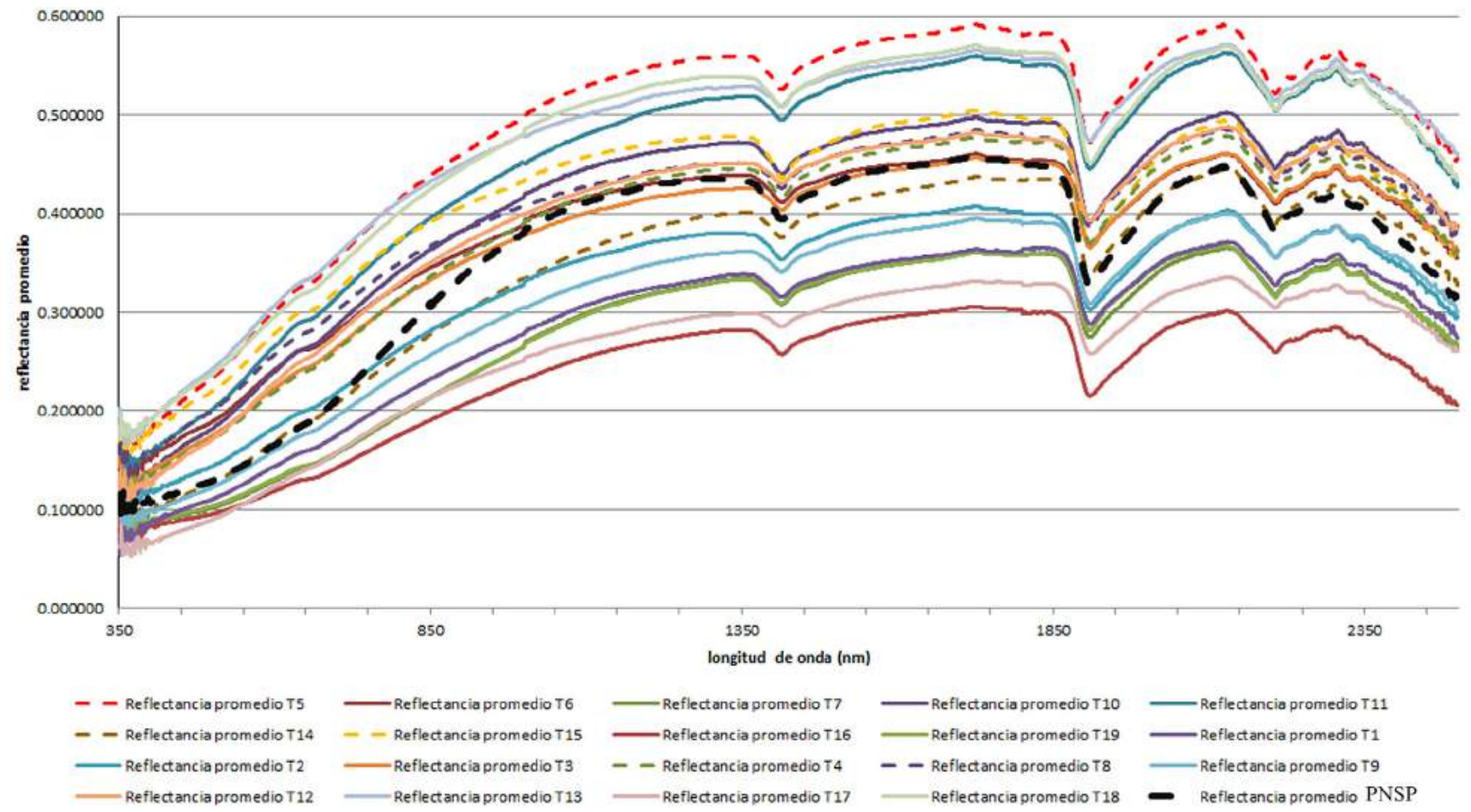

Figura 4 Reflectancias promedio de veinte muestras de suelo, incluyendo el Paleosuelo Negro San Pablo (PNSP). 
resulta en zonas de falso color anaranjadas y que se pueden relacionar con las estructuras arqueológicas marcadas en el mapa de Millon (1973) y con las zonas de mayor brillo sobre la superficie del terreno.

\subsection{MEDICIÓN DE LA REFLECTANGIA}

A partir de la radiación espectral fue posible obtener las reflectancias promedio y conocer la firma espectral de las muestras analizadas. Dichas firmas permitieron identificar los materiales presentes sobre superficie del terreno y compararlas con las del PSNP. Como se observa en la (Figura 4), 8 de las 19 muestras analizadas tuvieron una reflectancia mayor a la del PNSP, 7 se ubican por debajo, en tanto que 4 mostraron patrones similares. Con esta primera aproximación a los materiales, se se- leccionaron las 5 muestras T4, T5, T8, T14, T15, para comparar con el PNSP (Figura 5).

En el estudio de la reflectancia, se omitió la medición de las muestras de caliche y estuco debido a que por su alto contenido de carbonato de calcio, los valores que se observaban eran máximos, sin contraste al del blanco de calibración de Barita (Figura 5), de tal manera que no fue útil en el análisis.

\subsection{ANÁLISIS MIGROMORFOLÓGICO}

En el análisis de la micromorfología de las muestras de referencia fue imprescindible definir la microestructura que permitiera tener un patrón más claro con los patrones espectrales obtenidos. La descripción de las láminas delgadas se da a continuación:

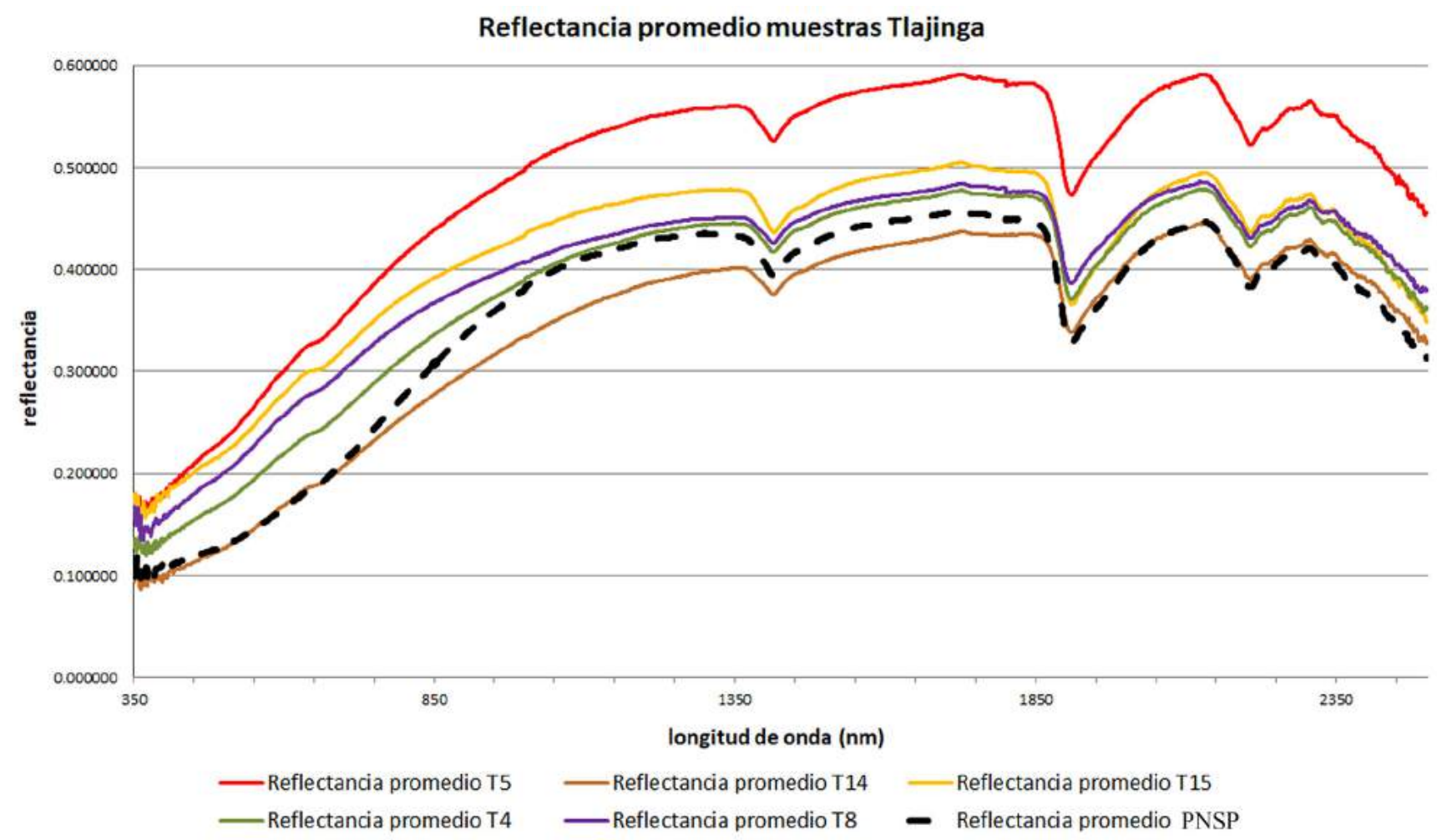

Figura 5 Reflectancias promedio de cinco muestras de suelo seleccionadas y del Paleosuelo Negro San Pablo (PNSP).) 


\subsubsection{MUESTRAS DE REFERENCIA}

Fragmento de piso de estuco. Recolectado en el área próxima a la estructura M48 de Tlajinga (Figura 3). Las láminas delgadas muestran el corte perpendicular a la superficie del piso para exhibir las capas que conforman su estructura interna (Figura 6a). La capa superior de estuco está perfectamente delimitada, observándose calcita tipo micrita y esparítica de color pardo claro. Inmersos en esta capa hay de vidrio volcánico bien clasificado en color negro (bajo luz polarizada). En la parte inferior hay óxidos de hierro, arcillas, algunos fragmentos de vidrio volcánico en color negro a pardo oscuro, y plagioclasas. Además del carbonato micrítico del estuco, se tienen áreas en las que se observan carbonatos naturales combinados con estructura globular (ooides), similares a las del caliche, lo cual sugiere que este último se reutiliza, como agregado, a los pisos teotihuacanos.

Caliche. La muestra de carbonato de calcio natural fue recolectada en las orillas del río San Lorenzo, al norte de Tlajinga. Bajo luz polarizada se observan los carbonatos micríticos con estructura globular de color pardo (ooides), con diámetros menores a $2 \mathrm{~mm}$, siguiendo una cierta configuración laminar-fluidal (Figura 6b). Además, se tienen áreas con arcilla de color parda. Destaca la presencia de minerales volcánicos como feldespatos, plagioclasas en color blanco, plagioclasas y ferromagnesianos alterados.

PNSP o "Paleosuelo Negro San Pablo". Forma parte del suelo original en el cual se asentó la cultura teotihuacana, el cual tiene propiedades de un Vertisol. La matriz es arcillosa con coloraciones oscuras debido a la impregnación de la materia orgánica. Hay también minerales volcánicos y muy poca calcita natural. La estructura es en bloques subangulares, con presencia de minerales primarios como plagioclasas. En los poros se observan películas arcillosas, delgadas, alrededor de los poros (Figura 6c).

\subsubsection{MUESTRAS DE SUELOS SELECCIONADOS}

Muestra T5. Contiene carbonatos de calcio culturales con esquirlas de vidrio volcánico bien clasificadas. Además de este material cultural, el suelo tiene carbonatos micríticos con fragmentos de plagioclasas (Figura 7a). Los diversos tipos de carbonato se diferencian por sus colores, siendo más claros los culturales y más pardos los naturales.

Muestra T15. La matriz en esta muestra de suelo es arcillosa y está impregnada con carbonatos micríticos de origen natural. Asimismo, se observan fragmentos de caliche con oolitos mezclados con
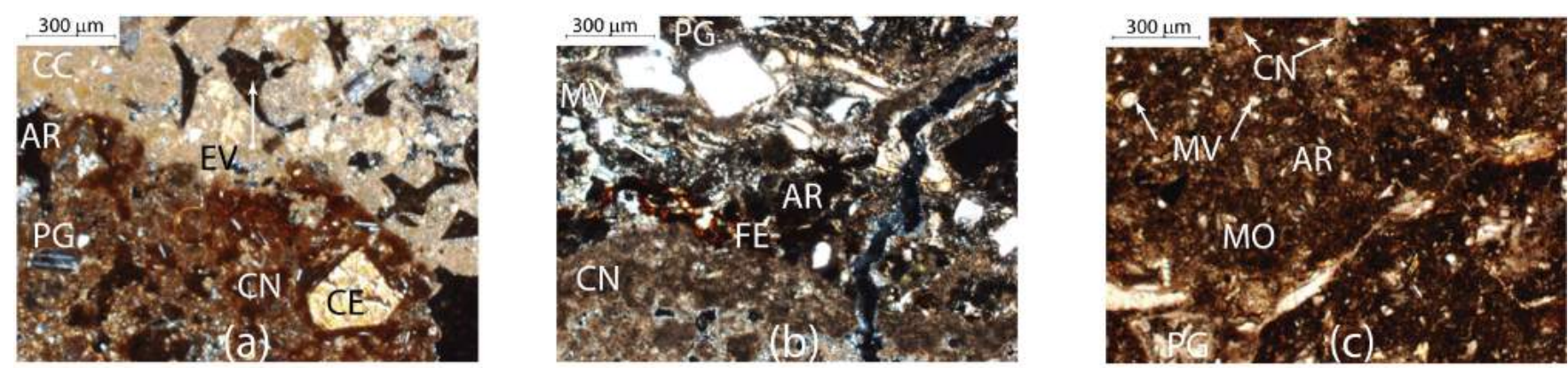

$\mathrm{CC}=$ Calcita cultural $\mathrm{CN}=$ Calcita natural $\quad \mathrm{CE}=$ Calcita Esparítica $\mathrm{EV}=$ Esquirlas de vidrio volcánico $\mathrm{FE}=$ Óxidos de Hierro $\mathrm{PG}=$ Plagioclasa $\mathrm{AR}=\mathrm{Arcilla} \mathrm{MO}=$ Materia orgánica $\mathrm{MV}=$ Minerales Volcánicos

Figura 6 Imágenes en luz polarizada, (a) Bloque calcita cultural micrítica, esquirlas de vidrio volcánico (parte superior en color crema) y calcita natural tipo caliche con ooides (parte inferior en color pardo). (b) Muestra de caliche con estructura globular en forma de ooides en color pardo, combinados con arcillas y minerales volcánicos. (c) Muestra de Paleosuelo Negro San Pablo (PNSP) con propiedades de un Vertisol. Acrónimos según leyenda. 
pequeños fragmentos de carbonato de calcio micrítico de origen cultural (Figura 7b). Hay cristales de plagioclasas, óxidos de hierro y otros minerales volcánicos.

Muestra T4. En esta lámina, los agregados de suelo tienen una matriz más gruesa (areno-limosa) con abundantes plagioclasas, con calcita tipo micrítica, posiblemente cultural y óxidos de hierro. La estructura es en bloques subangulares con alta porosidad (Figura 7c).

Muestra T8. Se observa un material con textura gruesa dominada por fragmentos de carbonato de calcio micrítico y ooidal de origen natural (caliche) y posiblemente cultural (estuco) y agregados de suelo con abundantes plagioclasas y minerales volcánicos alterados (Figura 7d).

Muestra T14. Es un suelo de matriz arcillosa impregnada con óxidos de hierro que le confiere una coloración rojiza. La fracción gruesa contiene minerales de origen volcánico (plagioclasas y ferromagnesianos) y una cantidad muy pequeña de calcita natural (Figura 7e).

\subsection{FLUORESGENGIA DE RAYOS X (FRX)}

Las gráficas comparativas de FRX para las muestras de referencia del caliche, estuco y PNSP exhiben características particulares.

El espectro de FRX para el estuco y el caliche exhibe una composición química que difiere apreciablemente del PNSP. Cuantitativamente este último posee menor contenido de $\mathrm{Ca}, \mathrm{Na}$ y $\mathrm{Mg}$, mostrando picos en $\mathrm{Si}, \mathrm{K}, \mathrm{Ti}, \mathrm{Mn}$ y Fe (Figura 8). En general, esta composición demuestra la mayor proporción de silicatos y de minerales ferromagnesianos, visibles en las láminas delgadas. Para el caliche se observan picos en $\mathrm{Ca}, \mathrm{Mg}, \mathrm{Al}$, $\mathrm{S}$ y $\mathrm{Cl}$, asociados a la mezcla con terrígenos de
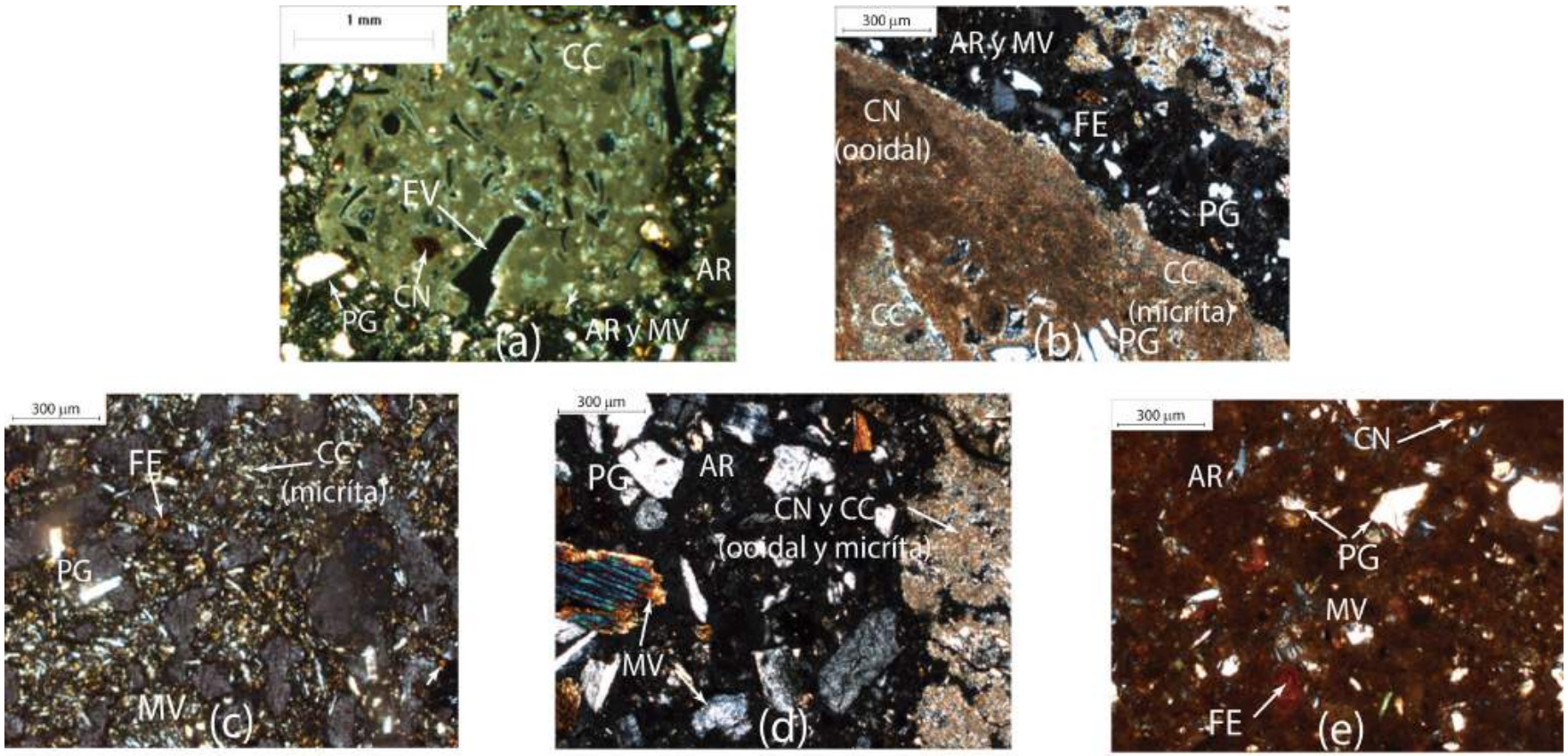

$\mathrm{CC}=$ Calcita cultural $\mathrm{CN}=$ Calcita natural $\quad \mathrm{EV}=$ Esquirlas de vidrio volcánico

$\mathrm{FE}=$ Óxidos de Hierro $\mathrm{PG}=$ Plagioclasa $\mathrm{AR}=$ Arcilla $\mathrm{MO}=$ Materia orgánica $\mathrm{MV}=$ Minerales Volcánicos

Figura 7 Imagen en luz polarizada plana, (a) Muestra T5 con esquirlas de vidrio volcánico, calcita de origen cultural y natural. (b) Muestra T15 de suelo con mezcla de calcita micrítica y con estructura tipo caliche. (c) Muestra T4 con calcita micrítica, óxidos de hierro y otros minerales volcánicos. (d) Muestra T8 con calcita tipo caliche y micrítica utilizada probablemente como base en la preparación de pisos de estuco. (e) Muestra T14 con calcita incipiente combinada con arcillas y minerales de origen volcánico. Acrónimos según leyenda. 


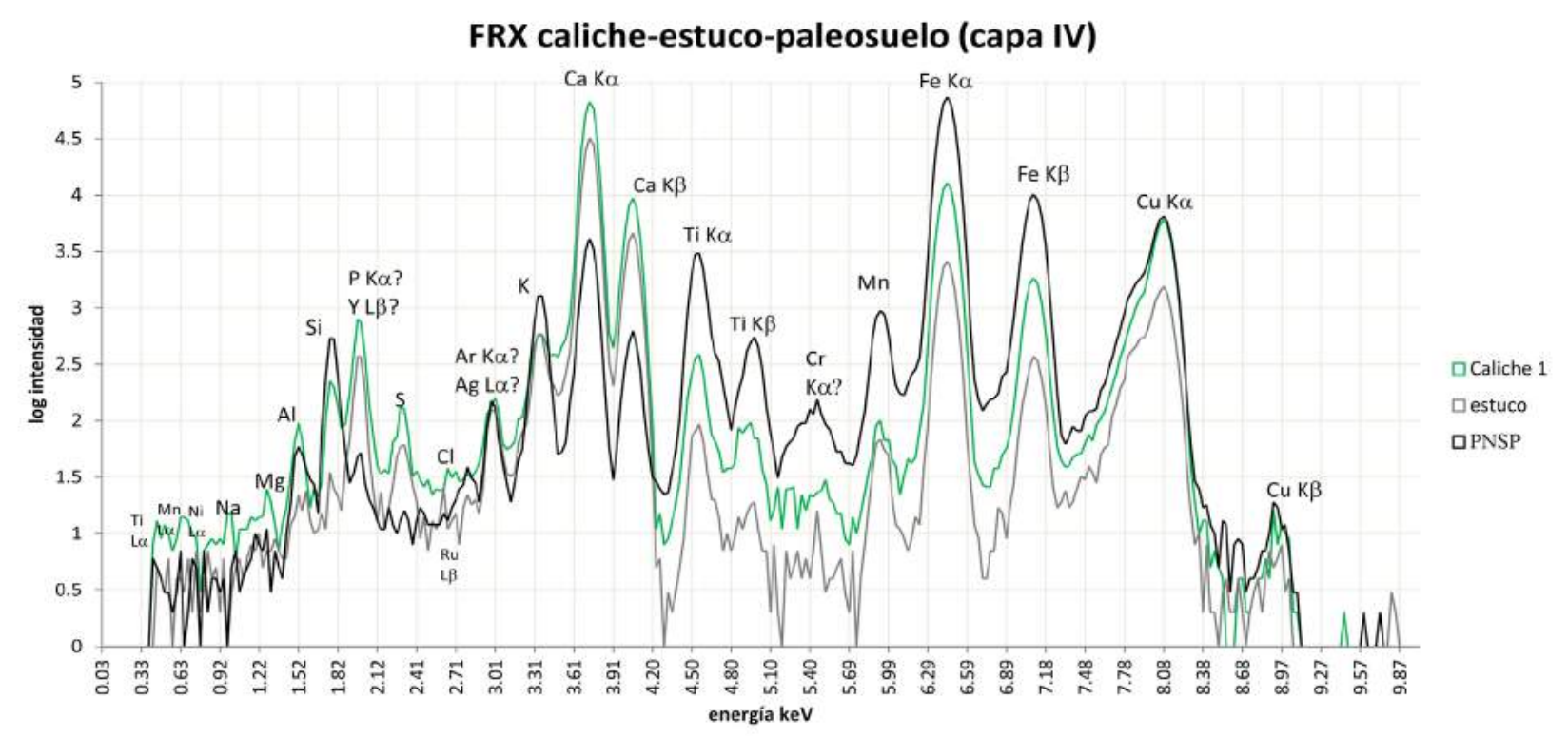

Figura 8 Comparación del contenido químico elemental por FRX del PNSP, caliche y estuco.

origen volcánico, destacando la alta proporción de Ca. A pesar de que tanto el estuco como el caliche están hechos principalmente de carbonato de calcio, tienen notables diferencias, sobre todo en el contenido de $\mathrm{Ca}, \mathrm{Al}, \mathrm{S}, \mathrm{P}$ y Mg.

\subsection{DIFRACGIÓN DE RAYOS X}

Los difractogramas de las muestras de referencia exhiben las concentraciones de las distintas fases minerales obtenidas. Las muestras de caliche y estuco teotihuacano tienen concentraciones muy similares de calcita, las cuales son ligeramente superiores en el estuco. En cuanto a las fases de otros minerales, el estuco presenta menor cantidad de arcillas, las cuales se supone son de origen pedogenético. Esto mismo se observa con las plagioclasas, que son más abundantes en el caliche. Otros minerales, como los anfíboles, están en mayor proporción en el estuco que en el caliche, además de contener un poco de dolomita (Figura 9, línea roja).

El PNSP difiere tanto del caliche y como del estuco, por su mayor proporción de arcilla y por la abundancia relativa de minerales de origen volcánico como plagioclasas, anfiboles, piroxenos y cuarzo (Figura 9, línea verde). Este paleosuelo, al estar clasificado como un Vertisol cálcico, posee en cantidades pequeñas carbonato de calcio pedogenético (Sánchez-Pérez et al., 2013), de modo que su presencia no es extraña (Figura 6c).

\section{Discusión}

\subsection{ANÁLISIS DE LOS MATERIALES ARQUEOLÓGICOS: DE LA MAGRO (PERGEPGIÓN REMOTA) A LA MICROESGALA (MICROMORFOLOGÍA)}

A partir del análisis de las componentes principales y los coeficientes de la matriz de correlación del procesamiento de las imágenes, se determina que las anomalías en el canal rojo, CP1, con alta reflectancia, corresponden con el brillo de todas las bandas (B01, B02, B03, B04), coincidiendo en gran parte con las estructuras reportadas en el mapa de Millon (1973). De esta forma, es posible proponer que dichos patrones son originados por los restos de materiales arqueológicos principalmente de carbonato de calcio cultural y natural, que al mezclarse con el suelo original, realza el brillo de la superficie del suelo. En el canal verde, 


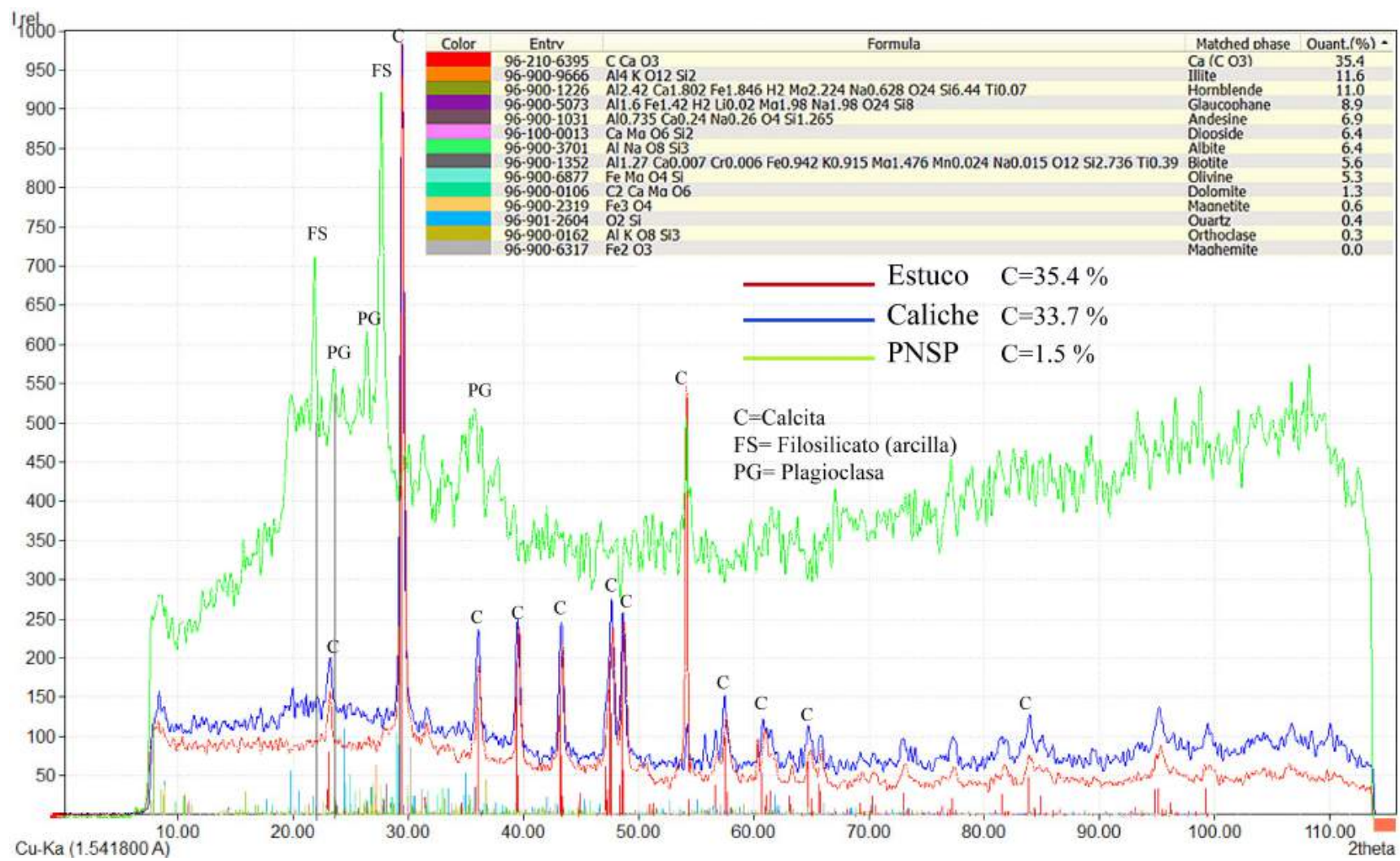

Figura 9 Difractogramas de las muestras de referencia caliche, estuco, PNSP y su correlación con la micromorfología.

CP2, se registra principalmente la respuesta de la vegetación en la banda infrarroja (B04). En contraparte, las zonas de bajas reflectancias en el canal azul, CP3, coinciden con zonas con menor cantidad de materiales de origen arqueológico y con ausencia de estructuras constructivas del mapa de Millon. Sin embargo, la interpretación de esta componente no es sencilla porque la curva azul es similar a la respuesta del agua en las bandas B01 al B04 (azul e infrarroja), y se puede interpretar que se deriva de la humedad en el suelo y de la vegetación (Figura 10).

En las zonas del terreno en donde se reconocen anomalías en las imágenes satelitales, es necesario combinar los resultados de la percepción remota con estudios de prospección geofísica, sobre y bajo la superficie del suelo, utilizando otras técnicas geofisicas que permitan conocer las dimensiones de las estructuras arqueológicas y su profundidad. Estás técnicas permitirían tener mayor certeza en la ubicación de las estructuras enterradas con respecto a las que se reportan en el mapa de Millon, y asimismo permitirían comprobar si los restos de materiales arqueológicos en superficie corresponden con la destrucción de las estructuras arqueológicas.

Sin embargo, estas metodologías de análisis son indirectas. Es por ello que en este trabajo se decidió hacer una comparación directa para definir si la firma detectada correspondía con las características de estos.

De acuerdo con los resultados de reflectancia promedio, el PNSP, el cual posee altos contenidos de arcilla y menos calcita de origen natural, se puede determinar si los patrones obtenidos en las muestras de suelo corresponden con el PNSP, o bien se trata de materiales mezclados con otros. Particularmente, la presencia de estucos aumenta el brillo y modifica la reflectancia de la superficie del terreno en forma significativa. De hecho, de 


\begin{tabular}{|c|c|c|c|c|}
\hline COMPONENTE & C1 & C 2 & C 3 & C 4 \\
\hline \% var. & 81.384654 & 11.286925 & 7.125101 & 0.20332 \\
\hline \% var. acumulativa & 81.716454 & 92.671579 & 99.79668 & 100 \\
\hline eigenval & 3.255386 & 0.451477 & 0.285004 & 0.008133 \\
\hline & & & & \\
\hline Banda & CP1 & CP2 & CP3 & CP4 \\
\hline B01 450-510 (nm) & 0.856292 & -0.336463 & -0.384033 & 0.004491 \\
\hline B02 510-580 (nm) & 0.970926 & -0.102182 & 0.21162 & -0.045596 \\
\hline B03 655-690 (nm) & 0.9606 & -0.068042 & 0.266112 & 0.042461 \\
\hline B04 780-920 (nm) & 0.814812 & 0.557023 & -0.160644 & -0.000465 \\
\hline
\end{tabular}

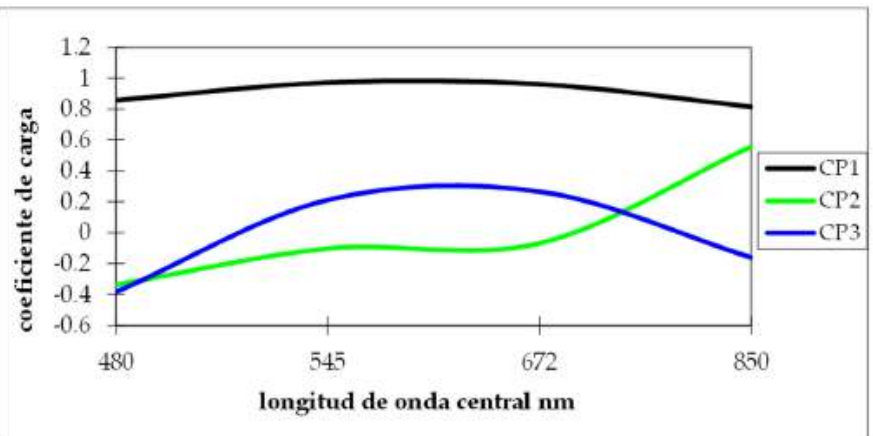

Matriz de carga obtenida a partir del análisis de componentes principales y representación gráfica de los coeficientes de carga.

acuerdo con las reflectancias obtenidas (Figura 4 y Figura 5), las más altas están asociadas con estructuras arqueológicas según el mapa de Millon (1973) (Figura 3). No obstante, la coincidencia no es perfecta, ya que por ejemplo, las muestras T4 y T8 son muy similares al PNSP, pero la T8 no se asocia a alguna estructura arqueológica. Sin embargo, es posible que no haya sido registrada por Millon (1973). Lo que sí es claro es que las reflectancias menores al PNSP generalmente no tienen estructuras asociadas.

Con base en la respuesta espectral cuantitativa de las muestras de suelo y las observaciones micromorfológicas, se clasificaron las muestras en tres grupos: de baja reflectancia (T14 y PNSP); de reflectancia media (T4, T8 y T15); de alta reflectancia (T5).

Es así que en la región del visible (390-700 nm) la reflectancia del PNSP tiene una respuesta similar a la muestra 14. La reflectancia en esta región, principalmente en el rojo, está asociada con la abundancia de óxidos de hierro y con suelos arcillosos. Para la región del infrarrojo cercano (700-1300 $\mathrm{nm})$ e infrarrojo medio (1300-2500 nm), la lámina delgada de la muestra T14 muestra coincidencias con el PNSP, por lo que puede concluirse que realmente la reflectancia permite determinar con claridad que T14 corresponde con el paleosuelo teotihuacano (Figuras 5 y 7 e).
Las muestras de suelo con reflectancia media y alta (T4, T8, T15) y (T5), respectivamente exhiben una curva con pendiente similar en la región del visible y parte del infrarrojo cercano (Figura 5). Para las muestras de reflectancia media, se puede apreciar un dominio de carbonato de calcio de origen natural similar al caliche, que en algunos casos está mezclado con el estuco, lo que origina los picos máximos de reflectancia, entre 2150 y $2300 \mathrm{~nm}$, donde los carbonatos tienen una respuesta significativa en el infrarrojo medio. Esta situación se refleja en los contenidos de calcita detectados por DRX, con $4.0 \%$ en T4 (Figura 12b), 3.2\% en T8 (Figura 12c) y 2.8\% en T15. El menor porcentaje está en T14 (0.9\%) (Figura 12e).

Para la muestra T5, los valores máximos de la reflectancia en todas las regiones del espectro se deben al aporte de materiales con carbonatos de calcio, principalmente de origen cultural, aumentando radicalmente la reflectancia del terreno, lo cual puede verificarse tanto en la curva espectral, en las láminas delgadas (Figura 5 y Figura 7a), como en la DRX, en donde precisamente T5 presenta los porcentajes más altos de calcita, 7.7\% (Figura 12a).

A pesar de que en la región de Teotihuacan, Manzanilla (2007) documenta que algunas micas, como la biotita o la muscovita, se usaron posiblemente para espejos y decorado, pudiendo incrementar 
la reflectancia, en este estudio no se detectaron cantidades abundantes de estos minerales. Es por ello que los resultados apuntan a que es la calcita la responsable de esta propiedad de los suelos.

Los minerales volcánicos encontrados en las muestras, como ferromagnesstas, plagioclasas e inclusive vidiro, están en distintas proporciones en los agregados utilizados para la preparación de las bases en los pisos y muros teotihuacanos. Una diferencia notable entre el estuco y el caliche, los cuales pueden ser confundidos ya que ambos son carbonatos de calcio, es que el caliche no sólo contiene carbonato de calcio, sino también arcillas y minerales de origen volcánico. En contraparte, el estuco, ahora transformado en carbonato de calcio, posee como agregados esquirlas de vidrio volcánico, además de minerales de origen volcá- nico utilizados como mortero, arcillas y también caliche de los afloramientos locales (Barba et al., 2009; Guillén, 2018).

\section{$5.2 \AA$ ES POSIBLE IDENTIFICAR LOS MATERIALES GULTURALES CON LA GOMPOSIGIÓN QUÍMICA DE LOS SUELOS EN TLAJINGA?}

Teotihuacan es una zona que se caracteriza por su geología dominantemente volcánica, que produce sedimentos con una composición similar (Vázquez y Jaimes, 1989). Las rocas carbonatadas no afloran en las cercanías. De esta manera, se podría pensar que la presencia de calcita (con sus picos dominantes en la FRX) sería un criterio claro para definir la presencia de estucos. Sin embargo, los resultados de este estudio demuestran que tanto

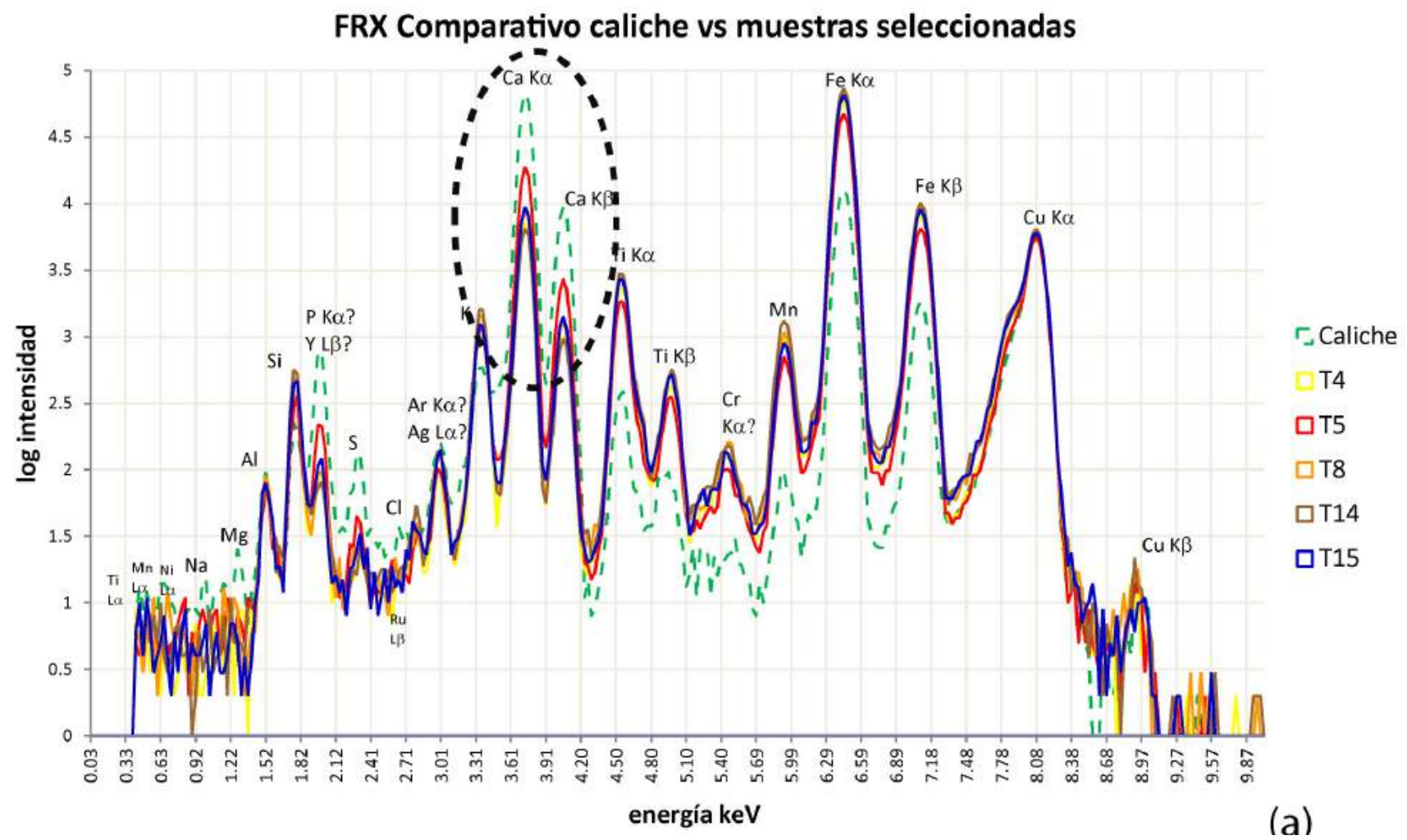


FRX Comparativo estuco vs muestras seleccionadas

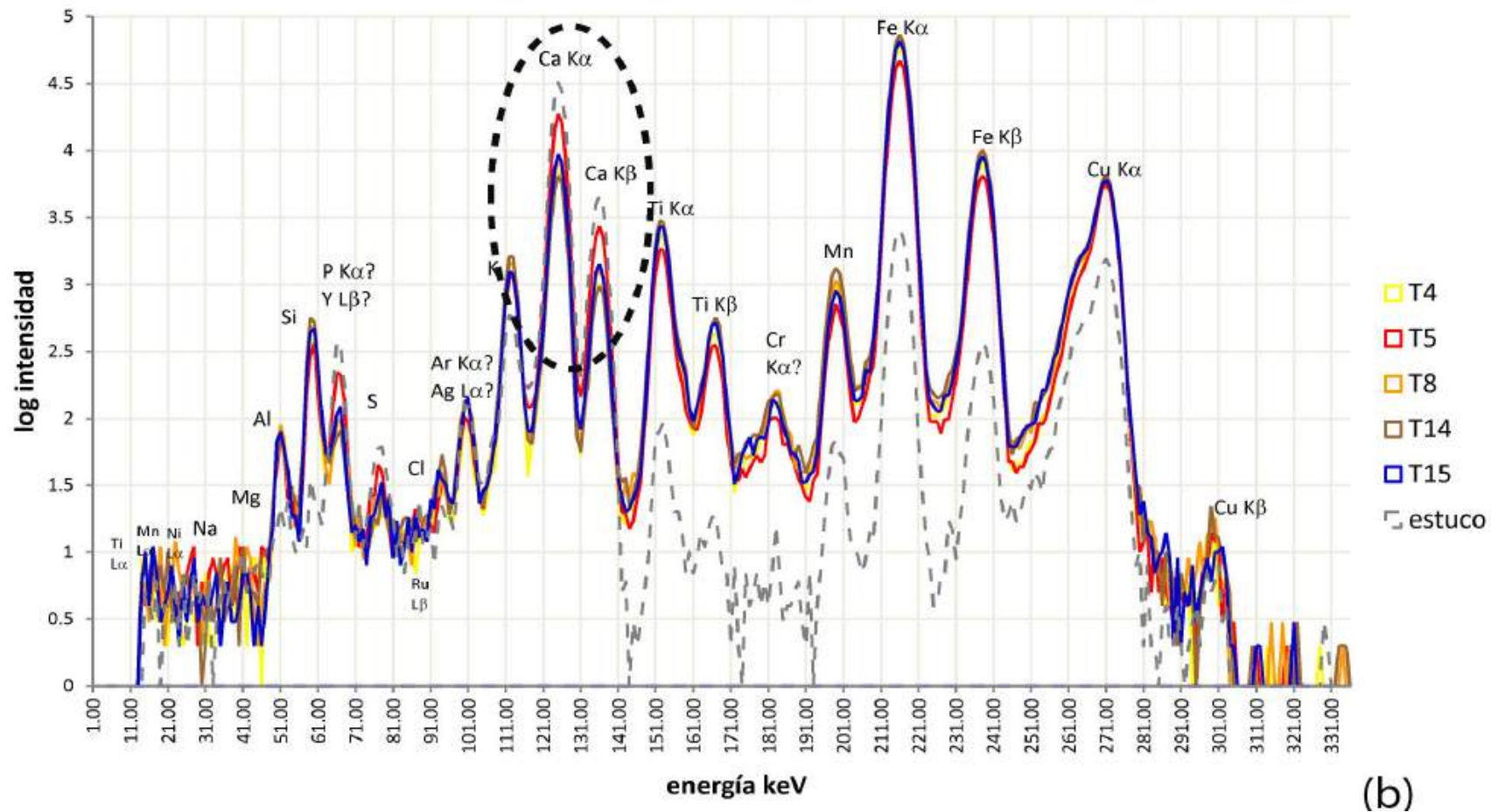

FRX Comparativo capa IV vs muestras seleccionadas

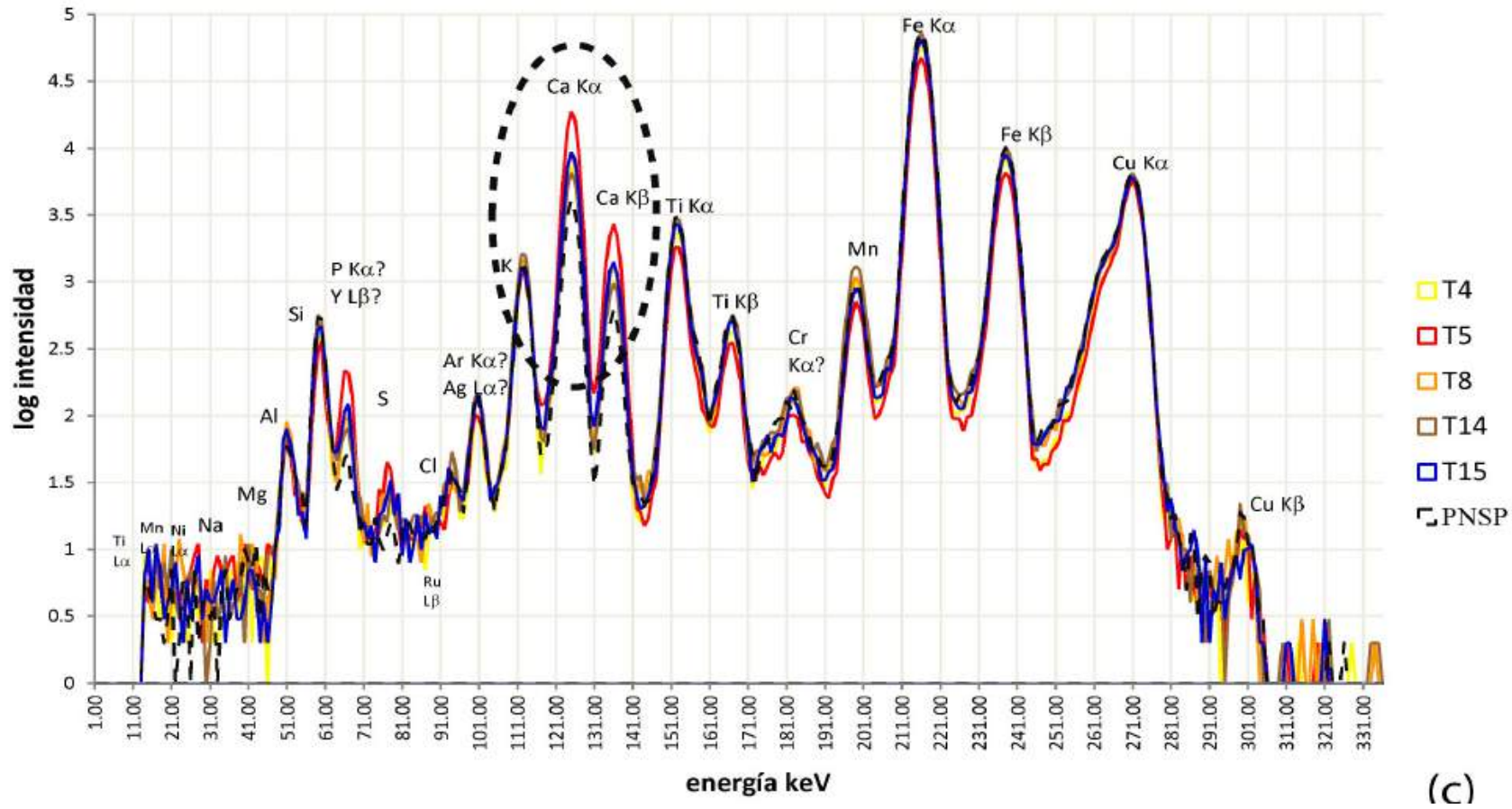

Figura 11 (Continuación) Comparación del análisis de FRX de: (a) caliche, (b) estuco y (c) PNSP con las muestras de suelo T4, T5, T8, T14 y T15.T14 y T15. 
los materiales culturales (estuco) como el caliche, de origen natural, son fuentes de carbonato de calcio. Ambos componentes contribuyeron al enriquecimiento de calcio en el suelo. Estos caliches son componentes comunes de los suelos de la región de Teotihuacan (Solleiro-Rebolledo et al., 2011, 2015; Valera, 2016).

Las gráficas de FRX del caliche y del estuco indican una composición química elemental con mayor proporción de la serie $\mathrm{K} \alpha$ y $\mathrm{K} \beta$ del Ca, en relación con las muestras de suelo seleccionadas, esto se debe a que el Ca es el elemento primordial y más abundante en el caliche y en el estuco $\left(\mathrm{CaCO}_{3}\right)$. Por otra parte, las muestras de suelo tienen mayor cantidad de elementos como el $\mathrm{Si}$, K, Ti, Mn y Fe, característicos de un suelo de origen volcanoclástico (Figura 11a y 11b).

Sin embargo, al comparar el contenido de calcio cultural (estuco) con la muestra de suelo T5, (Figura 11b) se observa una gran similiud. El análisis de la micromorfología confirma la presencia de carbonato de calcio cultural como componente principal, mezclado con esquirlas de vidrio volcánico para darle un tratamiento similar a la cal hidráulica (Barca et al., 2013).

El contenido químico elemental del PNSP y las muestras de suelo seleccionadas es prácticamente el mismo, esto se explica por el origen volcánico de estos suelos (Figura 11c). Por otra parte, hay pequeñas diferencias en el contenido de $\mathrm{Al}$, $\mathrm{P}, \mathrm{S}$, probablemente por la presencia de material orgánico en los perfiles edáficos actuales; esta hipótesis se tendría que probar. Sin embargo, la diferencia principal la observamos en el contenido de calcio $(\mathrm{Ca})$ de origen pedogenético (Solleiro et al., 2011; Sánchez et al., 2013) que es inferior en el PNSP y mayor en las muestras seleccionadas.

Por otro lado, el contenido químico elemental de los terrígenos en las muestras de suelo, en comparación con el caliche y el estuco, es notorio en $\mathrm{Ti}, \mathrm{Mn}$ y $\mathrm{Fe}$, esto debido a contener una mezcla de materiales naturales en mayor proporción con respecto a los de origen cultural cuyo principal aporte es el Ca.

\subsection{LA REFLECTANGIA Y SU RELAGIÓN GON LAS ESTRUGTURAS ARQUEOLÓGIGAS}

Esta tendencia la observamos directamente en la micromorfología, en donde la mayor cantidad de calcita se encuentra en las muestras T5 y T4 (Figura 12a y Figura 12b). En T5, según la micromorfología, hay dos tipos de calcita, cultural y natural, esta última mezclada con arcillas y empleada como base en la preparación de muros y pisos; mientras que la cultural corresponde con material original o reutilizado, reconocido en la lámina delgada con hábito micrítico y con esquirlas de vidrio volcánico (Figura 7a). La lámina delgada de T4 muestra principalmente calcita micrítica mezclada con arcillas en casi toda la muestra. Estas dos muestras son resultado de la destrucción de las estructuras registradas en el mapa de Millon (M47 y M48), y su alta reflectancia es reconocida en la imagen de componentes principales (Figura 3) y con el espectrorradiómetro de campo (Figura 5). Hay otras fases de minerales volcánicos y con abundancia de feldespatos, anfíboles, piroxenos. Para la muestra T8 (Figura 12c), el porcentaje de calcita disminuye hasta la mitad con respecto a T5, aumentando el porcentaje de minerales volcánicos. La zona en la que fue recolectada esta muestra tiene relación con las estructuras arqueológicas situadas al sur, formada por cuatro montículos (M7) conocidos como "El Palacio" (Millon, 1973), y al norte y este por cuatro (Figura 3). Millon no tiene reportada estructura alguna en este lugar con alta reflectancia; es probable que sea producto de los restos materiales de las estructuras circundantes o de una estructura que fue destruida.

En la muestra T15, clasificada con reflectancia media, las fases minerales de la calcita están presentes aunque ya en menor porcentaje (Figura 12d). Según la imagen de componentes principales (Figura 3) hay algunas estructuras asociadas, pero están a unos cien metros al sur, sureste y suroeste; y los restos materiales de estas estructuras pueden ser producto de la mezcla de materiales arqueológicos, principalmente de estuco y caliche, con arcillas y minerales volcánicos, transportados y drenados hacia el río Santiago, ubicado al norte. 


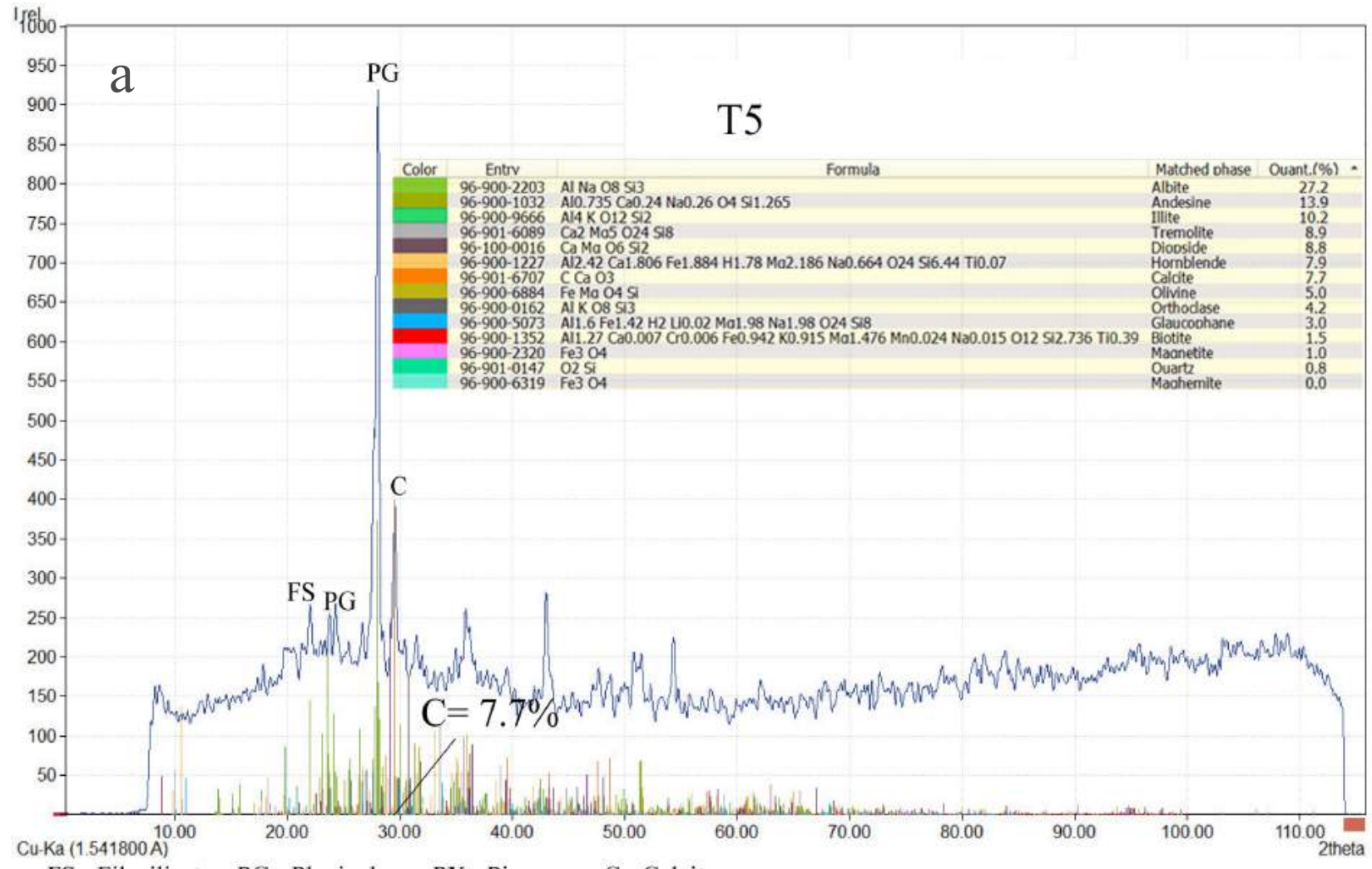

FS $=$ Filosilicatos $\mathrm{PG}=$ Plagioclasas $\mathrm{PX}=$ Piroxenos $\mathrm{C}=$ Calcita

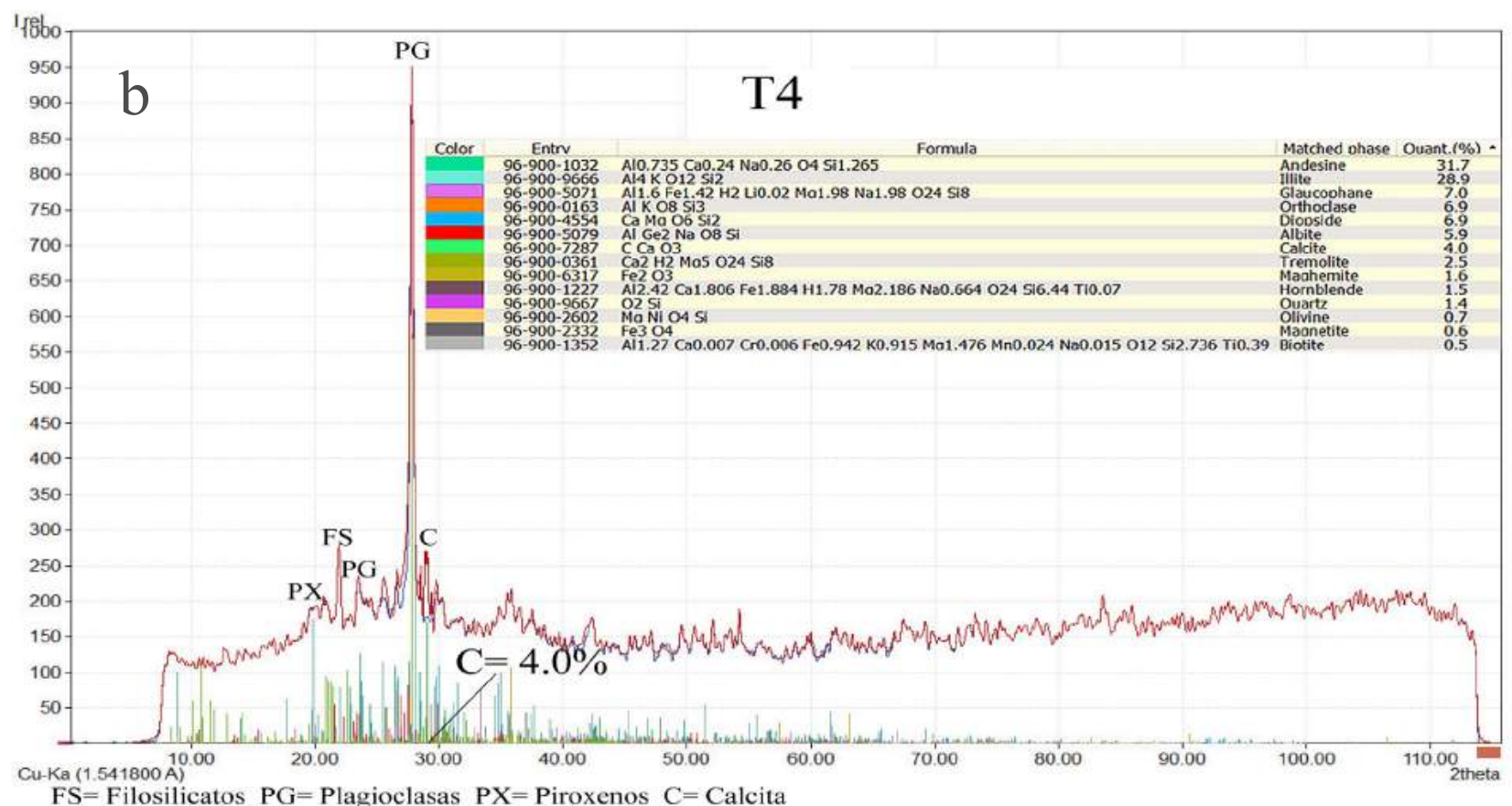

Figura 12 Comparativo de los difractogramas de las muestras de suelo (a) T5, (b) T4, (c) T8, (d) T15, (e) T14, con diferentes fases de minerales. 


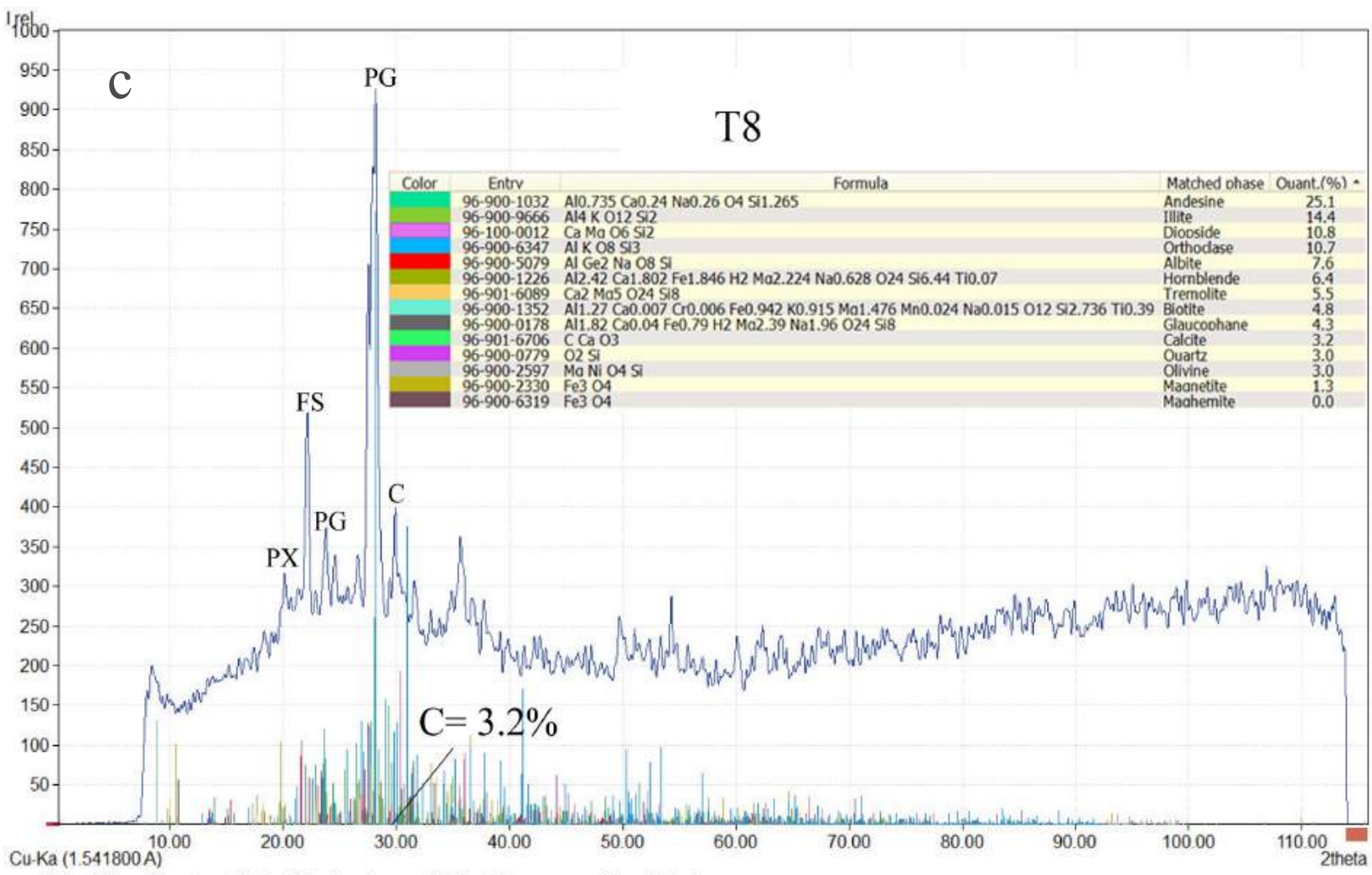

$\mathrm{FS}=$ Filosilicatos $\mathrm{PG}=$ Plagioclasas $\mathrm{PX}=$ Piroxenos $\mathrm{C}=$ Calcita

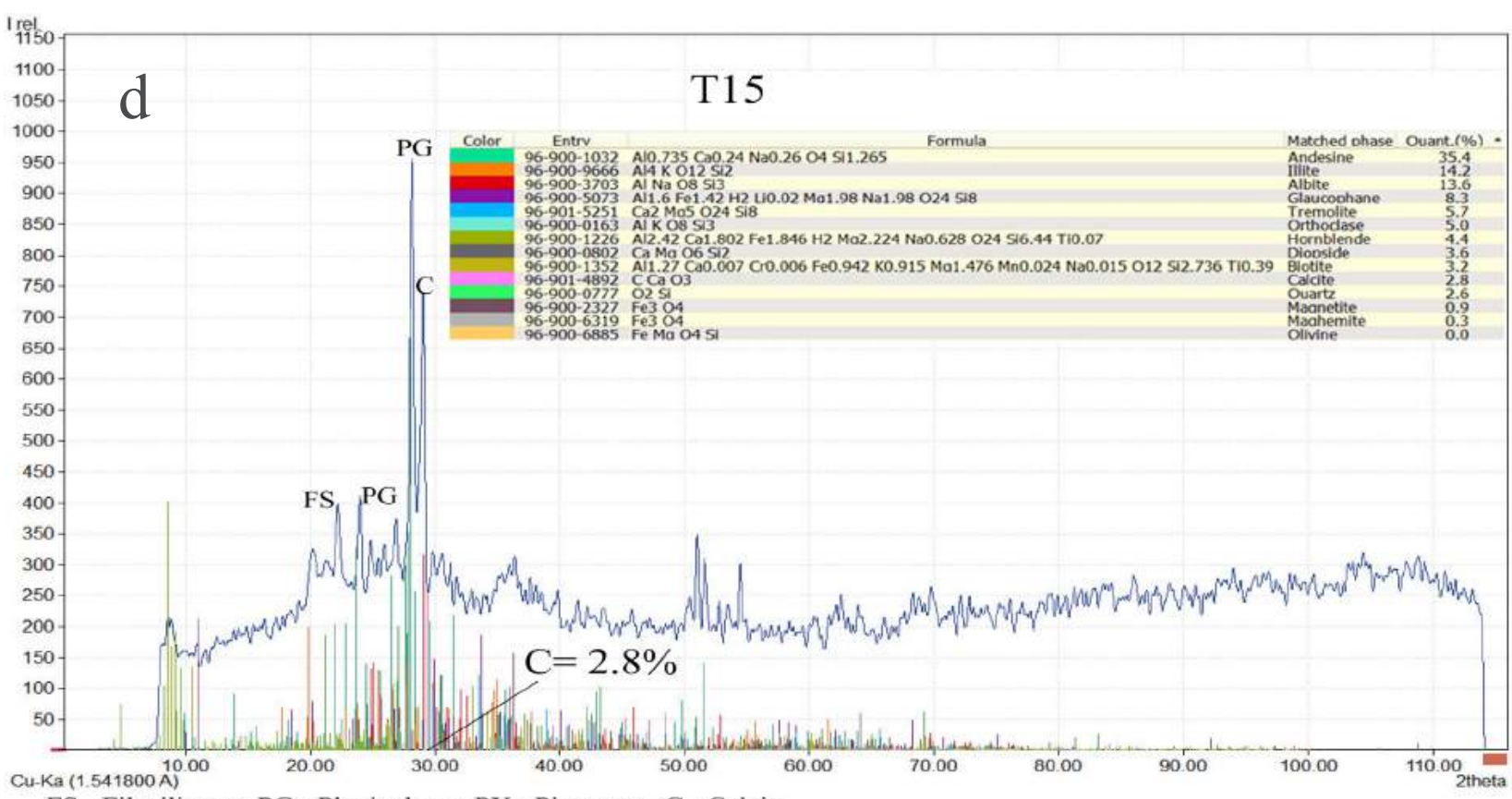

$\mathrm{FS}=$ Filosilicatos $\mathrm{PG}=$ Plagioclasas $\mathrm{PX}=$ Piroxenos $\mathrm{C}=$ Calcita

Figura 12 (Continuación) Comparativo de los difractogramas de las muestras de suelo (a) T5, (b) T4, (c) T8, (d) T15, (e) T14, con diferentes fases de minerales. 


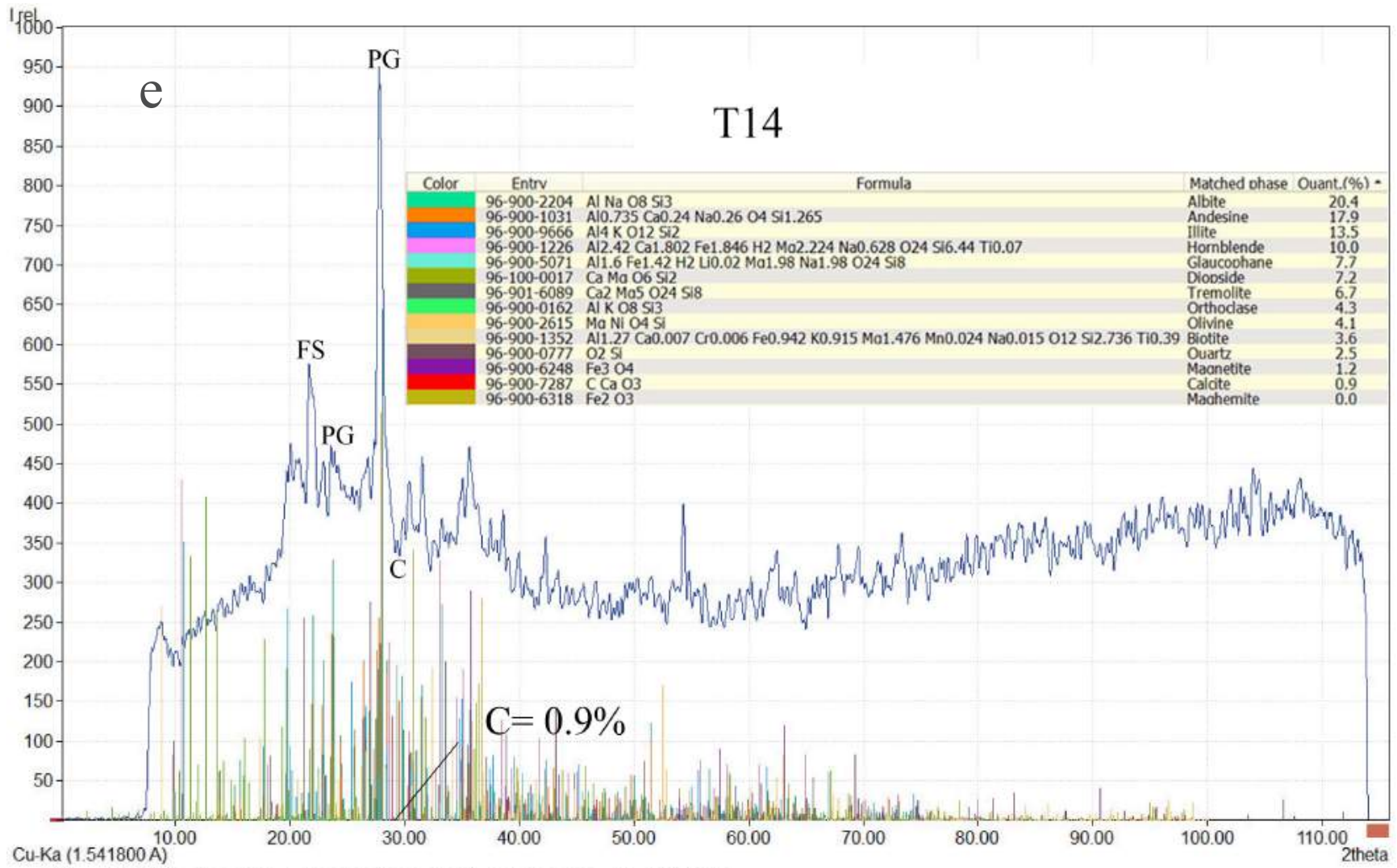

$\mathrm{FS}=$ Filosilicatos $\mathrm{PG}=$ Plagioclasas $\mathrm{PX}=$ Piroxenos $\mathrm{C}=$ Calcita

Figura 12 (Continuación) Comparativo de los difractogramas de las muestras de suelo (a) T5, (b) T4, (c) T8, (d) T15, (e) T14, con diferentes fases de minerales.

En contraparte, para la muestra T14, hay mayor proporción de arcillas y otros minerales volcánicos, y posee el menor porcentaje de calcita de todas las muestras de suelo analizadas, esto se puede explicar por la respuesta espectral del suelo en esta zona, correspondiente a un Vertisol de baja reflectancia con abundancia de arcillas y a la humedad.

\section{Conclusiones}

La imagen de componentes principales y el mapa de Millon (1973) revelan, desde un punto de vista sinóptico, en qué sectores de Tlajinga hay más coincidencias entre las estructuras arqueológicas y los materiales esparcidos en la superficie del suelo producto de su destrucción.

$\mathrm{El}$ análisis de micromorfología con láminas delgadas es muy útil para identificar con mayor certeza los carbonatos de origen natural y cultural, tanto en luz natural como en luz polarizada. Los de origen cultural (estucos) generalmente tienen textura micrítica con esquirlas de vidrio volcánico. Por otra parte, el carbonato de calcio natural, tipo caliche, posee un estructura distinta, que se identifica fácilmente por su micromorfología oolítica. Este análisis brinda parte de la evidencia física para demostrar que las muestras con reflectancia media y alta son debidas a la presencia de partículas de carbonato de calcio, las cuelas están esparcidas y mezcladas con la capa superior de suelo de textura principalmente arcillosa. Gran parte de las muestras son de la capa superior del suelo, donde aún existen estructuras arqueológicas enterradas (T5 y T4); y en otras donde han sido destruidas o queda muy poco de sus cimientos (T8, T14, T15).

De acuerdo con los resultados de este estudio se comprueba que las partículas de carbonato de calcio, mezcladas con la capa superior del suelo en esta región de Tlajinga, modifican y enriquecen el 
contenido mineralógico de los suelos, aumentando la reflectancia del horizonte superior del suelo, debido a las propiedades reflectivas intrínsecas de este mineral, principalmente en el visible e infrarrojo, y muchas de estas anomalías provienen de la destrucción de estructuras arqueológicas de la época teotihuacana.

$\mathrm{Al}$ analizar conjuntamente los resultados de la reflectancia medida con el espectrorradiómetro, la micromorfología, la FRX y la DRX, se puede determinar la relación entre los materiales arqueológicos diseminados en el horizonte superior del suelo, con las reflectancias de las distintas coberturas en las imágenes satelitales, y así establecer las coincidencias. Con esta información se puede conocer indirectamente la ubicación sobre la superficie de estructuras arqueológicas destruidas y otras enterradas aún intactas. Estas interpretaciones pueden ser comprobadas utilizando la prospección geofísica con gradiente magnético, geoeléctrica o con georradar, para realizar la excavación y comprobación de los resultados en áreas específicas.

El origen del carbonato de calcio cultural o natural se podría comprobar adicionalmente utilizando la espectroscopia infrarroja por transformada de Fourier (FTIR), esta técnica analítica está aún en desarrollo pero puede ser una técnica alternativa para determinar si durante su formación el carbonato de calcio fue sometido a procesos de calentamiento artificial (Chu et al., 2008).

\section{Referencias}

Barba, L., 1995, El impacto en la paleogeografía de Teotihuacan: México, Universidad Nacional Autónoma de México, Facultad de Filosofía y Letras, Tesis Doctoral, 92 p.

Barba, L., Blancas, J., Ortiz, A., Manzanilla, L., Barca, D., Crisci, G., Miriello, D., Pecci, A., 2009, Provenance of the limestone used in Teotihuacan (Mexico). A methodological approach: Archaeometry, 51 (4), 525-545.

Barca, D., Miriello, D., Pecci, A., Barba, L.,
Ortiz, A., Manzanilla, L., Blancas, J., Crisci, G., 2013, Provenance of glass shards in archaeological lime plasters by LA-ICP-MS: implications for the ancient routes from the Gulf of Mexico to Teotihuacan in Central Mexico: Journal of Archaeological Science, 40, 3999-4008.

Blancas, J., 2012, Percepción remota y técnicas geofísicas de prospección para el estudio de un asentamiento del Formativo en La Laguna Tlaxcala, México: México, Universidad Nacional Autónoma de México, Posgrado en Ciencias de la Tierra, Tesis de Maestría, 228 p.

Cabrera, R., 1996, Las excavaciones de La Ventilla. Un barrio teotihuacano: Revista Mexicana de Estudios Antropológicos, 42, 4-30.

Cabrera, R., 1998, El urbanismo y la arquitectura en La Ventilla: un barrio en la ciudad de Teotihuacan, Antropología e historia del occidente de México: México, Mesa Redonda de la Sociedad Mexicana de Antropología, XXIV, 1523-1547.

Cabrera, R., Gómez, S., 2008, La Ventilla: A model for a barrio in the urban structure of Teotihuacan, in Mastache, A.G., Cobean, R.H., García Cook, Á., Hirth, K.G. (eds.), El urbanismo en mesoamérica/Urbanism in Mesoamerica: Pennsylvania State University and Instituto Nacional de Antropología e Historia, 37-84.

Carballo, D., 2013, Proyecto arqueológico Tlajinga, Teotihuacan, Boston University, Universidad Nacional Autónoma de México: Solicitud presentada al Instituto Nacional de Antropología e Historia, Temporada 2013.

Chavez, S., 1996, Image-based atmospheric corrections - Revisited and Improved: Photogrammetric engineering and remote sensing, 62 (9), 1025-1036.

Chu, V., Regev, L., Weiner, S., Boaretto, E., 2008, Differentiating between anthropogenic calcite in plaster, ash and natural calcite using infrared spectroscopy: Implications 
in Archaeology: Journal of Archaeological Science, 35, 905-2011.

Gama-Castro, J., Solleiro-Rebolledo, E., McClung, E., Villalpando, J., Sedov, S., Jasso-Castañeda, C., Palacios-Mayorga, S., Hernández, D., 2005, Contribuciones de la Ciencia del Suelo a la investigación arqueológica: el caso de Teotihuacan: Terra Latinoamericana, 23 (1), 1-11.

Gamio, M., (ed.), 1979, La población del valle de Teotihuacan, México: edición facsimilar del Instituto Nacional Indigenista.

Guillén, K., 2018, Caracterización geoquímica de estucos y morteros de la zona arqueológica de Teotihuacan con una perspectiva de restauración y preservación: México, UNAM, Facultad de Ciencias, Tesis de Licenciatura, $61 \mathrm{p}$.

Hernández, J., 2007, Geología y geomorfología de la región de los yacimientos de obsidiana de Otumba en el sector norte de la Sierra Nevada de México: México, Universidad Nacional Autónoma de México, Facultad de Filosofia y Letras, Tesis de Licenciatura en Geografía, 125 p.

Manzanilla, L., 2006, Estados corporativos arcaicos. Organizaciones de excepción en escenarios excluyentes: Cuicuilco 13 (36), 13-45.

Manzanilla, L., 2007, Las “casas" nobles de los barrios de Teotihuacan: estructuras exclusionistas en un entorno corporativo: La Memoria 2007 de El Colegio Nacional, México, 453-470.

Manzanilla, L., 2009, Corporate life in apartment and barrio compounds at Teotihuacan, central Mexico: Craft specialization, hierarchy, and ethnicity, in Manzanilla, L. R. y Chapdelaine, C. (eds.), Domestic Life in Prehispanic Capitals: A study of specialization, hierarchy, and ethnicity: Ann Arbor, Museum of Anthropology, University of Michigan, 21-42.

Manzanilla, L., 2011, Sistemas de control de mano de obra y del intercambio de bienes suntuarios en el Corredor Teotihuacano hasta la Costa del Golfo en el Clásico: Anales de Antropología, 45, 9-32.

Millon, R., 1973, Urbanization at Teotihuacan, Mexico, Volume 1: The Teotihuacan Map. Part One: Text: Austin University of Texas Press, XVI, 154 p.

Millon, R., 1976, Social relations in ancient Teotihuacan, in Wolf, E. (ed.), In the Valley of Mexico: Studies in pre-Hispanic ecology and society: Albuquerque, University of New Mexico Press, 205-248.

Millon, R., 1981, Teotihuacan: City, State, and Civilization, in Jeremy Sabloff (ed.), Supplement to the handbook of Middle American Indians: Austin, University of Texas Press, Archaeology, vol. 1, 198-243.

Nichols, D., 1988, Infrared aerial photography and prehispanic irrigation at Teotihuacan: The Tlajinga canals: Journal of Field Archaeology, 15 (1), 17-27.

Ortiz, A., Barba, L., 1993, La química en el estudio de áreas de actividad, en Linda Manzanilla (ed.), Anatomía de un conjunto residencial teotihuacano en Oztoyahualco: México, Universidad Nacional Autónoma de México, 617-638.

Sánchez-Pérez, S., Solleiro-Rebolledo, E., Sedov, S., McClung de Tapia, E., Golyeva, A., Prado, B., Ibarra-Morales, E., 2013, The Black San Pablo paleosol of the Teotihuacan Valley, Mexico: Pedogenesis, fertility, and use in Ancient agricultural and urban systems: Geoarchaeology, 28, 249-267.

Solleiro-Rebolledo, E., Sycheva, S., Sedov, S., McClung de Tapia, E., Rivera-Uria, Y., Salcido-Berkovich, C., y Kuznetsova, A., 2011 , Fluvial processes and paleopedogenesis in Teotihuacan Valley, Mexico: Responses to the late Quaternary environmental changes: Quaternary International, 233, 40-52.

Solleiro-Rebolledo, E., Sedov, S., Sycheva, S., Sánchez, S.*, Pustovoitov, K., Sauer, D., 2015, Influencia de los paleosuelos en los procesos exógenos modernos en la porción 
noreste de la Cuenca de México: Boletín de la Sociedad Geológica Mexicana, 67 (2), 255-272.

Sullivan, K.S., 2006, Specialized production of San Martín orange ware at Teotihuacan, Mexico: Latin American Antiquity, 17, 23-53.

Valera, D., 2016, Carbonatos pedogenéticos en el Valle de Teotihuacan como indicadores paleoambientales: México, Universidad Nacional Autónoma de México, Posgrado en Ciencias de la Tierra, Tesis de Maestría, 82 p.

Vázquez, E., Jaimes, P., 1989, Geología de la Cuenca de México: Geofísica Internacional 28 (2), 133-189.

Widmer, R., 1987, The evolution of form and function in a Teotihuacan apartment compound: The case of Tlajinga 33, en E.
McClung de Tapia y E. C. Rattray (eds.), Teotihuacan: Nuevos Datos, Nuevas Síntesis, Nuevos Problemas: México, Instituto de Investigaciones Antropológicas, Universidad Nacional Autónoma de México, 317-368.

Widmer, R.J., 1991, Lapidary craft specialization at Teotihuacan: Implications for community structure at 33:S3W1 and economic organization in the city: Ancient Mesoamerica, 2 (1), 131-147.

Widmer, R.J., 1993, Social organization and household structure of a Teotihuacan apartment compound: S3W1:33 of the Tlajinga barrio, in Santley, R.S., and Hirth K.G. (eds.), Prehispanic domestic units in western Mesoamerica: Studies of the household, compound, and residence, : Boca Raton, CRC Press, 87-104. 